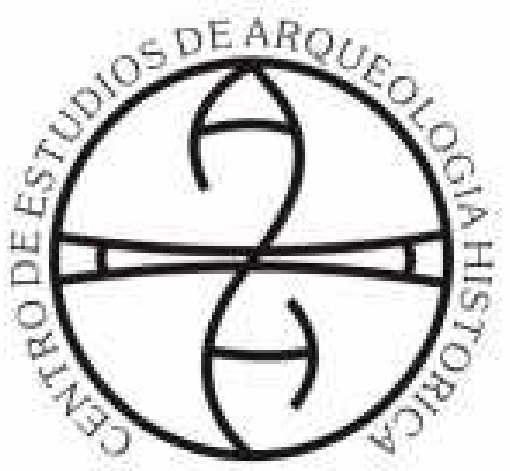

Centro de Estudios de Arqueología Histórica Universidad Nacional de Rosario

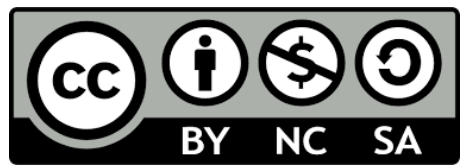

Teoría y Práctica de la Arqueología Histórica Latinoamericana | Año X, Volumen 12 | 2021

Revista del Centro de Estudios de Arqueología Histórica, Facultad de Humanidades y Artes, Universidad Nacional de Rosario https://teoriaypracticaah.unr.edu.ar/index.php/index https://rephip.unr.edu.ar/handle/2133/14804

ISSN en línea: 2591-2801

ISSN versión impresa: 2250-866X

Atribución-NoComercial-CompartirIgual 4.0 Internacional (CC BY-NC-SA 4.0)

https://creativecommons.org/licenses/by-nc-sa/4.0/deed.es

Julio Fabián Merlo (ID.: https://orcid.org/0000-0001-9897285X), María del Carmen Langiano (ID.: https://orcid. org/0000-0001-9909-4147) y Pablo Ormazabal (ID.: https:// orcid.org/0000-0001-7575-1755). Los enclaves fronterizos al sur del río Salado, lugares de interacción interétnica (siglo XIX)

\title{
LOS ENCLAVES FRONTERIZOS AL SUR DEL RÍO SALADO, LUGARES DE INTERACCIÓN INTERÉTNICA (SIGLO XIX)
}

\section{The Frontier enclaves SOUTH OF THE RÍo SALAdo, Places OF INTER- ETHNIC INTERACTION (XIX CENTURY)}

\author{
Julio Fabián Merlo*, María del Carmen Langiano** y Pablo Ormazabal***
}

\section{Resumen}

En este trabajo se presenta una síntesis de la documentación generada a lo largo de los años de investigación en sitios de frontera del siglo XIX, centro de la provincia de Buenos Aires. Los documentos y la cultura material recuperada en las diferentes tareas de campo dan cuenta de la interacción de las comunidades originarias y los eurocriollos instalados en tierra dentro.

Los sitios arqueológicos analizados están relacionados con una de las principales rastrilladas denominada "Camino de los Chilenos", que conectó hasta el siglo XIX diferentes enclaves que luego dieron origen

* INCUAPA CONICET-UNICEN, Facultad de Ciencias Sociales. Olavarría, Buenos Aires, Argentina. jmerlo@soc.unicen. edu.ar

** INCUAPA CONICET-UNICEN, Facultad de Ciencias Sociales. Olavarría, Buenos Aires, Argentina. mariadelcarmenlangiano@gmail.com

*** Profesor del Instituto Superior de Formación Docente $\mathrm{N}^{\circ}$ 22, Olavarría. Departamento de Arqueología. Facultad de Ciencias Sociales. Universidad Nacional del Centro de la Provincia de Buenos Aires, Argentina. pablo.ormazabal@yahoo. com.ar 
a partidos y localidades, que formaron parte de la Frontera Sur y Oeste de la región pampeana (Langiano, et al. 2002; Merlo, et al. 2017). Los mismos representan el avance fronterizo desde principios del siglo XIX, hasta su culminación (1880).

Los enclaves que se presentan a continuación son aquellos que poseen evidencias arqueológicas contundentes sobre la relación de ambas sociedades; principalmente los que formaron la Frontera Sur. El resto de los sitios que no se analizan en este artículo también presentan realidades de la interacción, pero con disminución de casos. Estas conexiones menos notables pueden ser producto de la dinámica de los estratos sedimentológicos pampeanos, la actividad agrícola y el crecimiento urbano. El reuso constante de los lugares donde se investiga complejiza relacionar la cultura material de ambas sociedades. Sin embargo, la documentación escrita aporta valiosos datos aunque, en ciertas circunstancias, presenta sesgos tanto por parte del escribiente de documentos como del diseñador de la cartografía de esa época.

Palabras clave: frontera - indígenas - eurocriollos - fortificaciones - siglo XIX

\begin{abstract}
This work presents a synthesis of the documentation generated throughout the years of research in border sites of the XIX century, central Buenos Aires province. The documents and the material culture recovered in the different field tasks give an account of the interaction of the original communities and the eurocriollos settled on the land within.

The archaeological sites analyzed are related to one of the main trails called "Camino de los Chilenos", which connected different enclaves until the XIX century that later gave rise to parties and localities, which were part of the South and West Border of the Pampean region. (Langiano, et al. 2002; Merlo, et al. 2017). They represent the frontier advance from the beginning of the XIX century, until its culmination (1880).

The enclaves presented below are those that have strong archaeological evidence on the relationship of both societies; mainly those that formed the Southern Border. The rest of the sites that are not analyzed in this article also present interaction realities, but with a decrease in cases. These less notable connections may be the product of the dynamics of the Pampean sediment strata, agricultural activity, and urban growth. The constant reuse of the places investigated makes it difficult to relate the material culture of both societies. However, the written documentation provides valuable data although, in certain circumstances, it presents biases both on the part of the document clerk and the designer of the cartography of that time.
\end{abstract}

Keywords: frontier - natives - eurocriollos - fortitications - XIX century

\title{
Introducción
}

En este trabajo se presentan las investigaciones desarrolladas desde mediados de la década de 1990 (Figura 1) en el proyecto se analizaron diferentes sitios arqueológicos correspondientes al período de contacto eurocriollo e indígena en la Frontera Sur y Oeste de la Provincia de Buenos Aires (Siglo XIX). 


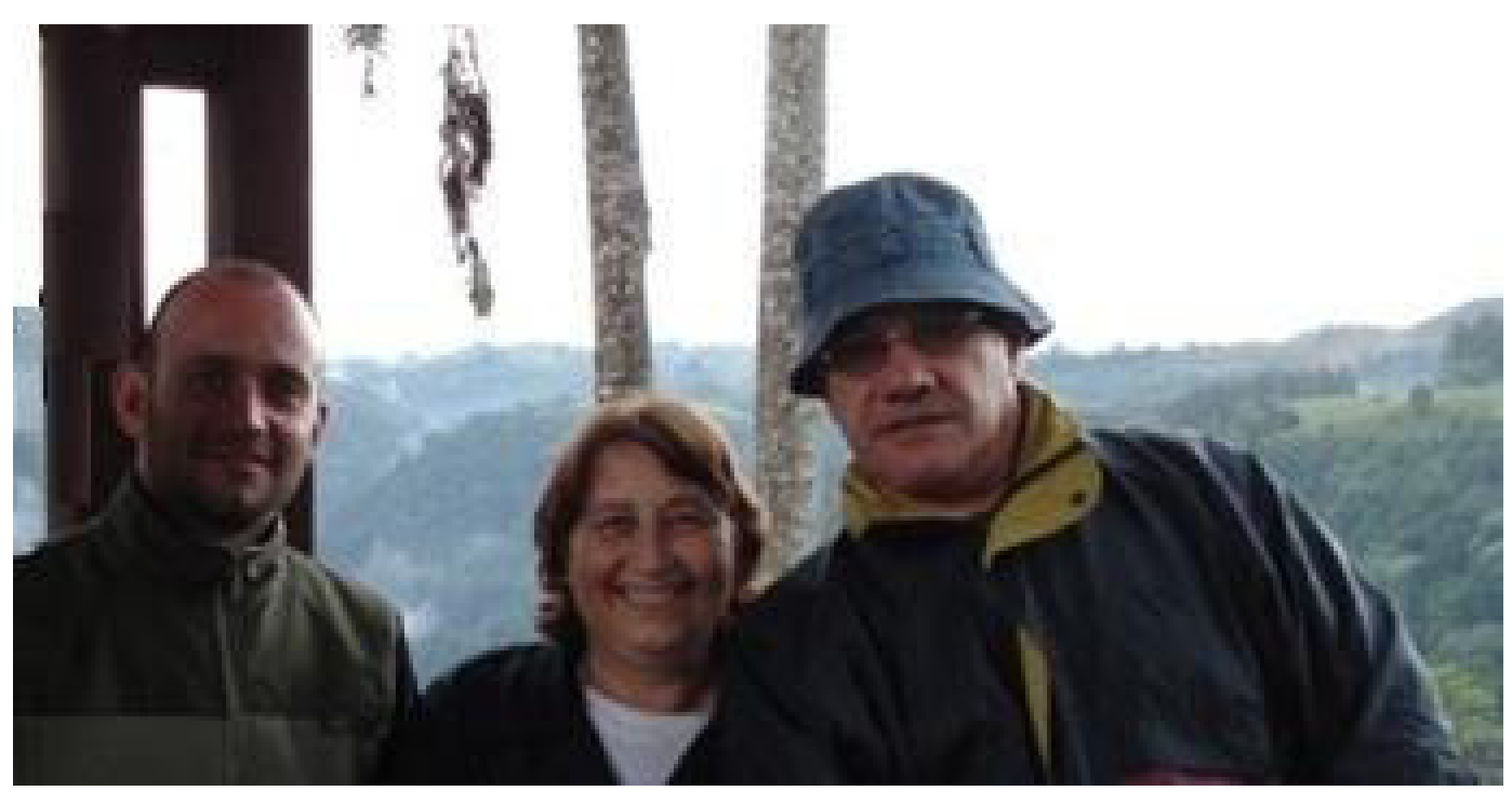

Figura 1. Grupo Dr. investigación en Arqueología postconquista (INARPOS) de la Facultad de Ciencias Sociales de la Universidad Nacional del Centro de la Provincia de Buenos Aires FACSOUNICEN.

Tras años de pesquisas se logró cumplir con el objetivo de caracterizar las relaciones interétnicas utilizando documentos escritos, la memoria oral y el registro de la cultura material recuperada. Estas observaciones permitieron registrar la convivencia entre los eurocriollos del llano y las comunidades originarias, consideradas por diferentes fuentes como "indios amigos" (Ratto, 2003). Éstas se instalaban en las proximidades de las fortificaciones al Sur del Río Salado bonaerense, con la finalidad de efectuar intercambios sociales y comerciales de manera pacífica. En algunos de los sitios como el Fortín El Perdido (1865) o el Fuerte Lavalle (1872) se observó en la estratigrafía la ocupación de la fortificación sobre vestigios arqueológicos de población originaria. Esta estratificación pudo ser el producto de desplazamientos pacíficos, como una forma de negociación o de manera forzada generando conflictos bélicos. Cabe aclarar que esta categorización como indios amigos; aliados u hostiles, planteada por Ratto, en la década del 1990, sigue vigente en la memoria colectiva actual. En aquellas comunidades que establecen buenas relaciones con los gobiernos de turno, independiente de su postura política, se los consideran "indios buenos" y aquellos grupos rebeldes ante las estrategias actuales son considerados "mapuches hostiles" y no se establecen sistemáticas estrategias de diálogo y consensos para respetas sus reclamos. El objetivo de esta divulgación no es analizar las políticas indígenas actuales, sino simplemente, hacer una reseña histórica de la convivencia pacífica entre comunidades originarias y eurocriollos cuando el estado argentino estaba en el proceso de formación y unificación.

Desde la arqueología se han trabajado sitios históricos que formaron parte de las fronteras del siglo XIX, previas a la conquista del "desierto" iniciada por Roca a mediados de la década de 1870. Estos enclaves fronterizos, desde la historia, en su mayoría fueron considerados fortificaciones netamente militares, pero nuestra postura es más amplia puesto que los consideramos lugares de interacción donde 
predominaron los períodos de intercambios pacíficos, con esto rompemos la idea de un constante conflicto bélico. De todos modos, si bien los conflictos estuvieron presentes en determinados momentos, no fue lo que predominó en estas sociedades o grupo étnicos que denotaban diferencias sociales y culturales.

Los sitios con evidencias de interacción interétnica son los Fuertes Independencia (1823), Blanca Grande (1828) y Lavalle (1872) San Martín (1872), los Fortines El Perdido (1865 y, La Parva (1858) (Langiano, et al. 1997, 2002; Merlo, 1997, 1999, 2014, entre otros). No podemos dejar de mencionar aquellos sitios que muestran interacción de ambas sociedades que han sido trabajados por otros investigadores que registraron los hallazgos arqueológicos de las sociedades del siglo XIX. Entre estos podemos mencionar al Fortín Miñana o Nueva Esperanza que fue fundado cerca de las nacientes del arroyo Azul a raíz del requerimiento de los propios vecinos de Azul hacia fines de 1860, "medida que fue oficializada a principios de 1861" (Gómez Romero, 1999:24). El posterior avance de las estancias y las poblaciones criollas determinó su abandono hacia mediados de 1863, trasladándose unas seis leguas hacia el este -a la zona donde nace el arroyo Tapalqué- y dando origen al Fortín El Perdido (Langiano, et al. 2009). Por otro lado, en el sitio Arroyo Nieves 1 y 2, se presentan los resultados de los trabajos de campo arqueológicos realizados en el Arroyo Nieves. Allí se localizan contextos arqueológicos de poblaciones aborígenes posthispánicas, y el registro material en su mayoría arrojó restos arqueofaunísticos de especies domésticas y fragmentos de distintos tipos de recipientes vítreos, junto con algunos elementos líticos, restos de loza, ladrillo y de objetos de metal. Estos materiales son entrecruzados con las evidencias documentales y cartográficas (Pedrotta, 2002).

En la Frontera Oeste se estudia el Fuerte General Paz (1869), en un período que estuvo marcado por la presencia de un conjunto de emplazamientos militares diseñado para marcar la presencia efectiva del estado en la región con la finalidad de continuar el proceso de apropiación de los territorios de las comunidades originarias ubicados al Oeste de la actual provincia de Buenos Aires. A través del análisis de fuentes documentales escritas y cartografía se describen elementos materiales y simbólicos de este proceso de modificación del espacio físico y social, detallando las distintas intervenciones en el espacio emprendidas para "domesticar el desierto" (Leoni, et al. 2013).

La ubicación y estudio de los fortines El Bagual (1869), Loncagüé (1863), Illescas (1863), Clalafquén (1863), Picaso (1855), Pozo Pampa (1858), Tapera de Hinojo (1863), Tapera del Medano (1863), Laguna Don Pancho, El Comisario (1872), Asentamiento de Coliqueo, laguna la Azotea, y la zona rural de Bragado; del partido de Nueve de Julio, Bragado y Los Toldos, aún requieren continuar con los relevamientos y trabajos de campo (Merlo, et al. 2017, Figura 2).

El centro de la provincia de Buenos Aires constituye un área clave para comprender los últimos períodos del proceso de desarrollo de las poblaciones aborígenes pampeanas, las cuales alteraron rápidamente diversos aspectos de su economía, tecnología, patrones de asentamiento, vínculos sociales y sistemas de valores, como consecuencia del contacto y paulatino avance de la frontera y los cambios políticos generados desde la era rosista hasta la asunción del partido Autonomista Nacional y sus variantes políticas internas en el Ministerio del Interior.

\section{La frontera y el paisaje pampeano en el siglo XIX}

Para 1820 la instalación de puestos fortificados al Sur del río Salado, implicaba costos muy altos (Merlo, 1999), sumado a los remanentes climático de la "pequeña edad del hielo" (Politis, 1984). No obstante, este esfuerzo estaba justificado por la necesidad de integrar los territorios y asentar población eurocriolla al Sur del río Salado de la provincia de Buenos Aires, para resguardarse del avance continen- 


\section{FRONTERAS DEL SIGLO XIX}

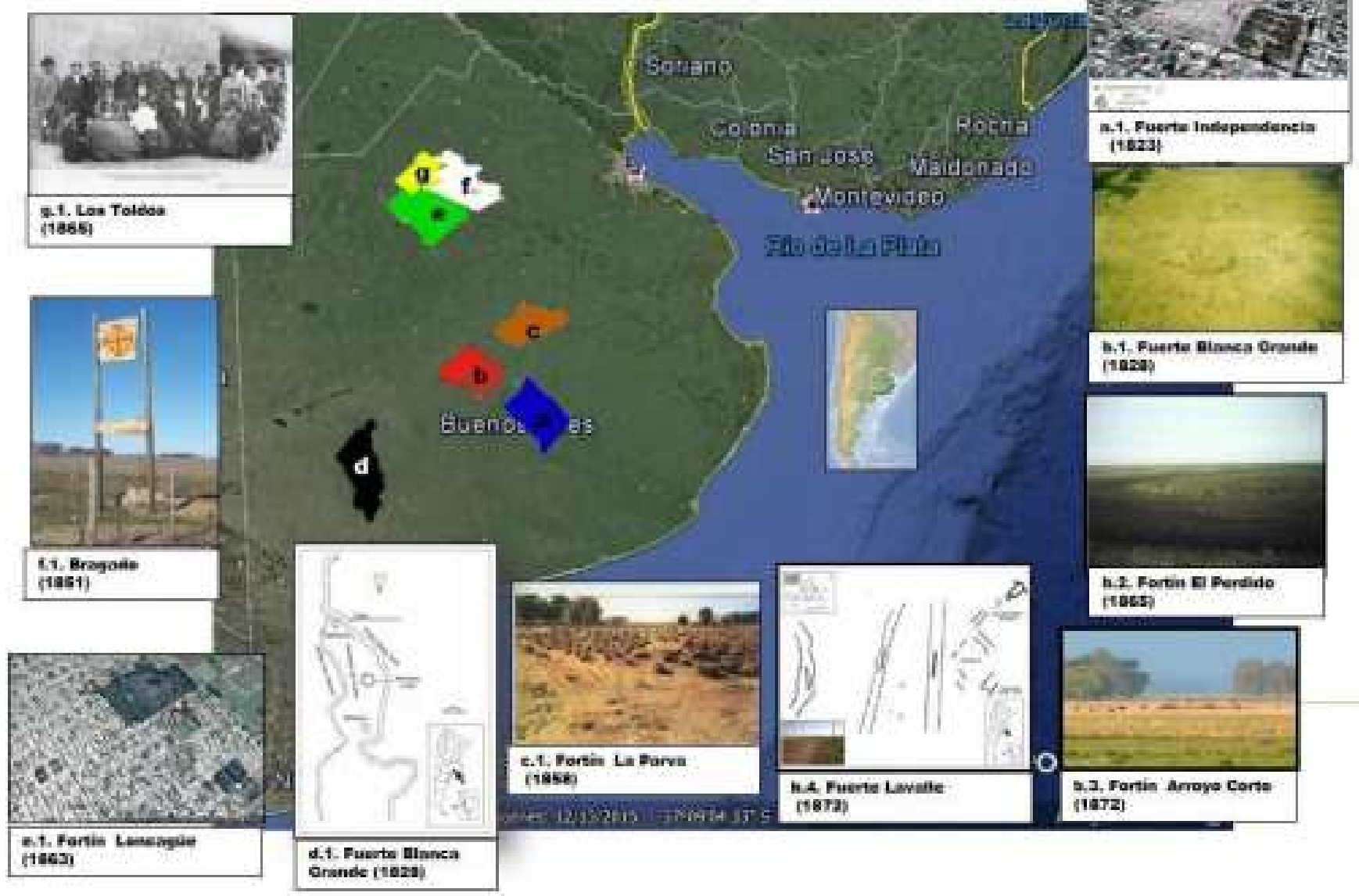

Figura 2. Algunos de los sitios trabajados de la Frontera Sur y Oeste de la Provincia de Buenos Aires, siglo XIX.

tal de Inglaterra y del imperio del Brasil por los puertos de Buenos Aires y Carmen de Patagones. Cabe recordar que el 6 de marzo de 1827, un ataque sorpresivo de la Marina brasileña bloqueó el puerto de Buenos Aires y desembarcó en el puerto de Carmen de Patagones, con fines de conquistar tierras. Este riesgo permanente aceleró la necesidad de construir nuevas líneas de frontera, estableciendo límites precisos de la provincia (Merlo, 2014). Pero este avance al interior del continente, no pudo ser posible en un contexto bélico constante con las comunidades originarias, de ser así, el avance de las potencias extranjeras hubiera sido concretado. Desde la historia, se remarcó la superioridad bélica del estado con su tecnología armamentística europea (Walther, 1970). El registro arqueológico y los datos aportados por los diarios de campaña donde constan la recuperación de cautivas o intercambios de productos comerciales, como la sal, muestran lo contrario ya que los pobladores de tierra adentro no se diferenciaban, ni social, ni económicamente con los grupos nativos.

Las comunidades originarias se destacaban por negociar por su bienestar y lo concretaban mediante parlamentos que normalmente duraban varios días y se tomaban decisiones en un contexto festivo. 
Esto era de interés prioritario para los diferentes caciques que interactuaron con los representantes del incipiente estado a lo largo del siglo XIX. Se plantearon negociaciones que la elite o terratenientes del lado occidental solían no respetar, debido a intereses políticos y económicos personales o acuerdos con las potencias extranjeras, como el imperio Británico, descuidando o incumpliendo los pactos de palabra o escritos establecidos con las sociedades indígenas. Estos tratados dependían muchas veces de las intenciones de los proveedores y de los comandantes de frontera. El ejemplo más emblemático es el de Martín Rodríguez, quien atacó a los nativos que lo habían ayudado a instalar el Fuerte Independencia; luego de esta hazaña, es ascendido a gobernador de la provincia de Buenos Aires. Lentamente se establecieron límites de la frontera; donde los eurocriollos, sin más recursos que lo que podían extraer de la tierra e intercambiar con las sociedades originarias, se fueron instalando como colonos bajo la voluntad del terrateniente o militar que recibió como pago la tierra y los lugares de caza de los grupos originarios.

Con el auge de la generación del 80 y con el gobierno de Roca se agrava la situación, estableciéndose los límites territoriales del país, desmembrando, o eliminando las redes de intercambio económico y social entre eurocriollos e indígenas. Se instalan las redes ferroviarias y en el territorio por donde pasaban las vías del tren se construyen galpones para el mantenimiento de las máquinas y casas para los operarios, Todo esto era de propiedad británica y todos los recursos se transportaban al puerto de Buenos Aires para el comercio asimétrico inglés.

La lucha de poder por dominar los espacios se inició con la llegada de los españoles a América y sus potencias rivales como Inglaterra y Portugal. Esta situación continúo en las disputas internas de la política criolla; Rosas versus Urquiza; Buenos Aires y la Confederación (Goldman, 1998). Los porteños se sobrepusieron, con el apoyo anglo francés y a partir de 1862, bajo el gobierno de Bartolomé Mitre, se inició el período denominado de "Organización Nacional" (Lobato y Suriano, 2010) y se concentró el poder del presidente de la Nación en el entonces gobernador de la provincia de Buenos Aires. Esta política incluyó la instalación de fuertes, fortines y cantones que marcarán una fuerte presencia del ejército estatal y la incorporación de nuevos colonos e inmigrantes europeos, que impulsarán el crecimiento de la producción rural, así como el desarrollo de pueblos a partir de los nuevos asentamientos localizados alrededor de los puestos fortificados. El proceso de avance del gobierno nacional incluyó la refundación del Fuerte Blanca Grande (1869) y la .instalación de nuevos puestos fortificados (e.g.: Fuerte Lavalle (1869) y los Fortines Veterano (1867), Vigilancia y Veterano Chico (1870), Arroyo Corto (1872), Olavarría y Fe (1876), entre otros. También se potenció el crecimiento de la Frontera Oeste.

El trazado de líneas de frontera interior también provocó un cambio en el paisaje pampeano. La percepción occidental del espacio en función de los objetivos de apropiación de tierras es física, con fines económicos y contrasta con la racionalidad de los pueblos originarios (Langiano y Merlo, 2010). Para estos últimos el paisaje se conforma a partir de una compleja trama que involucra un fuerte sentimiento de arraigo y pertenencia, donde se crean y recrean los mitos y los relatos ancestrales (Curtoni, 2000). La racionalidad eurocriolla comenzó a imponerse a partir de 1829 mediante el reparto de "suertes de estancia" en la zona del arroyo Azul (Lanteri, 2004). Entonces se fraccionaron tierras, que fueron donadas con el compromiso de asentarse en el lugar. Esto implicó la reubicación y reducción de los espacios usados por los indígenas, como fue el caso de los" indios de Catriel" que fueron trasladados a tierras poco productivas (Figura 3) o la Zanja de Alsina para separar la "barbarie" de la "civilización", por último la introducción del alambrado (circa 1850) para cercar y establecer divisorias de campos en la pampa bonaerense, lo que aumentó el conflicto con la racionalidad indígena, cuyo paisaje fue alterado, restringiendo el uso y la circulación por determinados lugares ancestralmente ocupados. Así, se conformó un paisaje donde interactuar, generar asentamientos, huellas y principalmente caminos, conocidos en el área de estudio 
como "rastrilladas" que Paunero denominó "Camino de los indios a Salinas", Melchert "Camino de los Chilenos" y Alsina, al instalarse las líneas telegráficas, "Camino del hilo" (Paunero, 1864; Melcher, 1873; Alsina, 1977 [1877]; Figura 4).
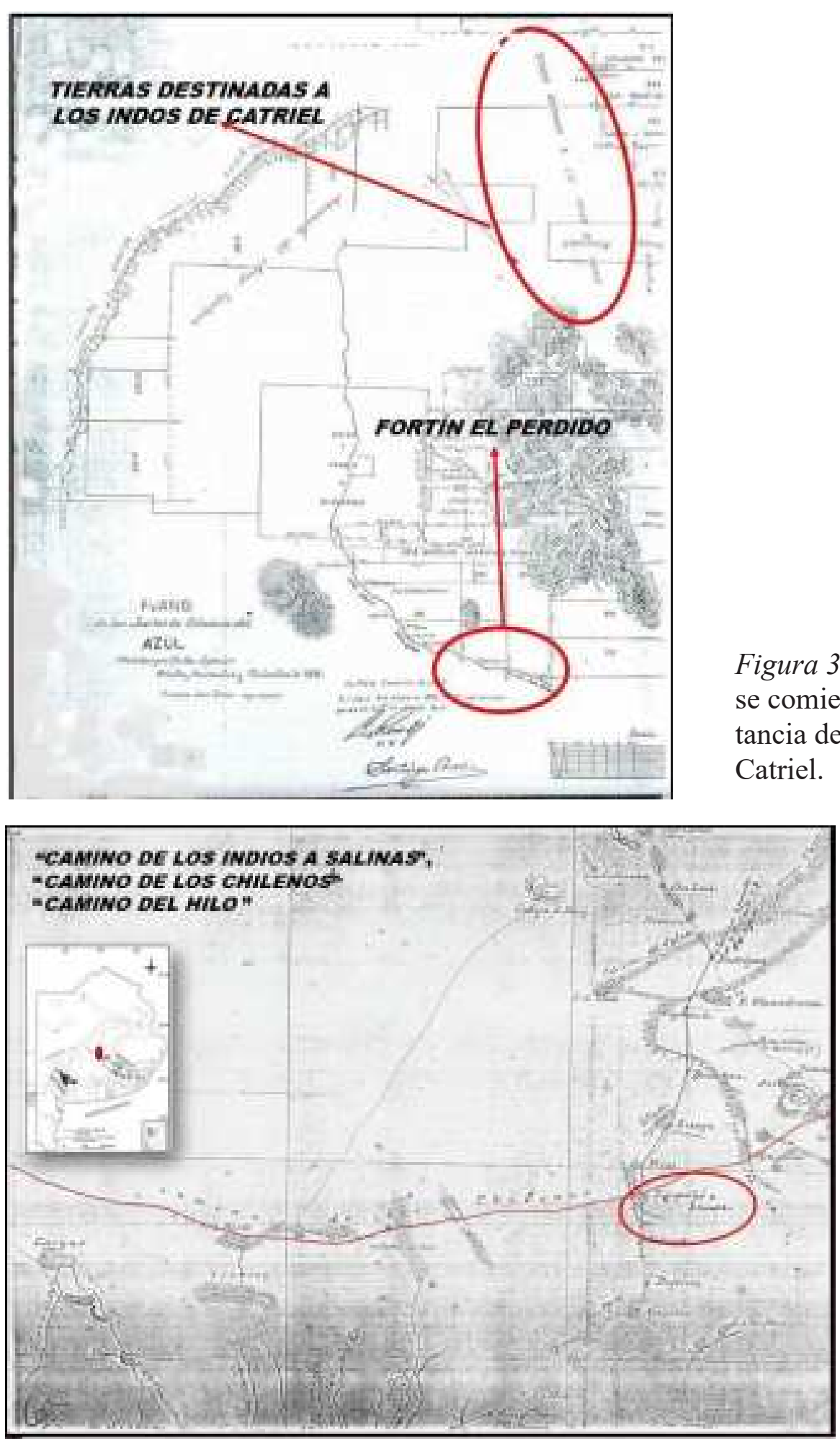

Figura 3. Mapa de Arce de 1872, donde se comienza a diagramar las suertes de Estancia del Azul y se reubica a los indios de Catriel.
Figura 4. Rastrillada denominada Camino de los Chilenos, actual Ruta Nacional No 60 .
Los enclaves fronterizos al sur del río Salado, lugares de interacción interétnica (siglo XIX)

Páginas 133-158 


\section{Los sitios arqueológicos}

A continuación se hará una breve descripción de algunos de los sitios incluidos en este artículo. Por cuestiones de espacio para la publicación de este trabajo se decidió presentar los sitios en donde más se evidencian la interacción entre los eurocriollos y las comunidades originarias.

\section{Fuerte Independencia}

Situado en el mismo espacio donde luego se construyeron diferentes edificaciones del centro de la ciudad, donde ya no quedan restos visibles del fuerte en la actualidad. Originalmente fue emplazado en un valle de las sierras de Tandil, en cercanías de la cuenca del arroyo Tandileufú. Su forma era poligonal, semejante a una estrella de cinco puntas y en su edificación se emplearon piedras de la zona (Gorraiz Beloqui, 1958). La fecha oficial de su fundación es 1823 y fue desmantelado a mediados de la década de 1860. Si bien la posición aislada de esta fortificación no permitió consolidar la línea de frontera, tal como había sido planeado, resulta de interés recuperar su información ya que constituyó la primera avanzada de importancia hacia tierra adentro, en el sistema serrano de Tandilia, perdurando hasta transformarse en el pueblo de Tandil (Figura 5).

\section{AVANCES EN LAS INVESTIGACIONES ARQUEOLÓGICAS ; FI}

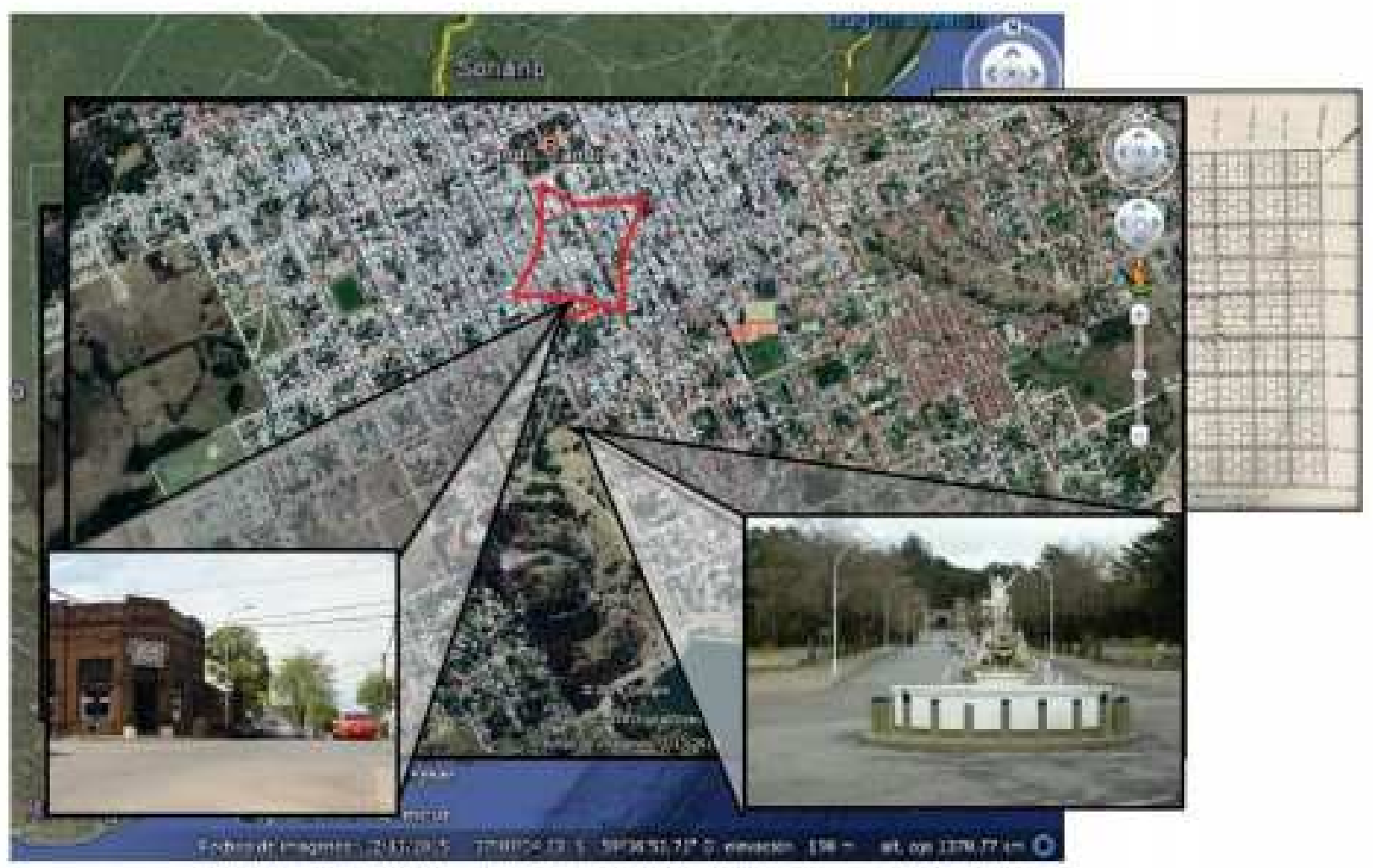

Figura 5. Ubicación estimativa del Fuerte Independencia. 
Los trabajos arqueológicos se iniciaron en el patio de la Iglesia Danesa, construida en 1873 y que preserva su patio original, ubicada en la calle Maipú entre General Rodríguez y 9 de Julio. Se excavó una trinchera de tres cuadrículas, donde se pudo detectar material previo y posterior a la fundación del fuerte; hallazgos de artefactos de procedencia de pueblos originarios asociados a material de origen europeo, como de ítems que dan cuenta del uso continúo del espacio hasta la actualidad (Figura 6).

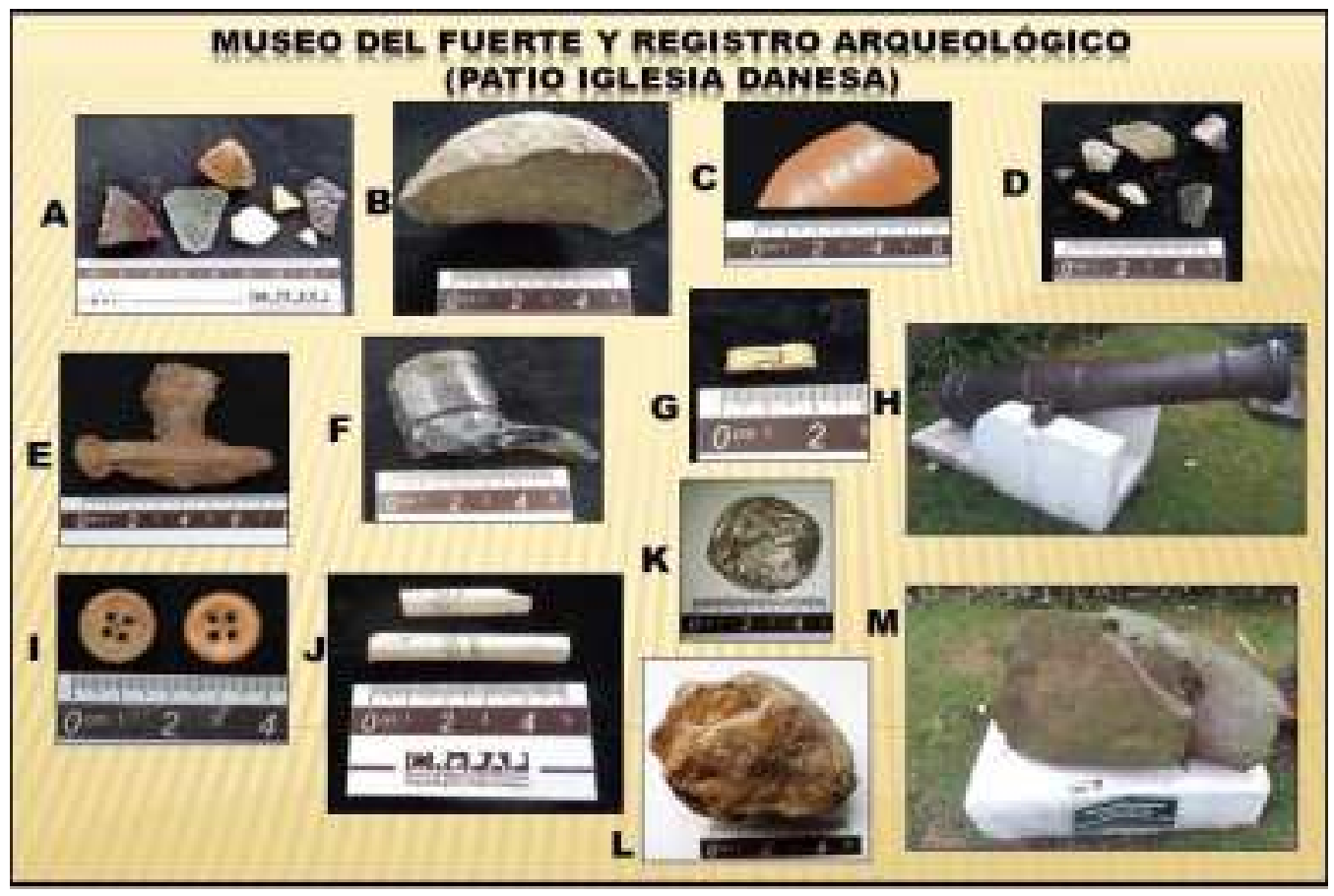

Figura 6. Materiales recuperados en las excavaciones realizadas en el patio de la Iglesia Danesa.

Los materiales corresponden a: (A) fragmentos de vidrios de las ventanas de la Iglesia, (B) fragmento de boleadora, (C) fragmento del cuerpo de un porrón de ginebra confeccionado en gres, (D) fragmentos óseos quemados y calcinados, usados para realizar fuegos; (E) un picaporte de puerta, (F) botellas sopladas sin molde y con los picos cortados a tijera, (G) placas dérmica de Dasypus hybridus (mulita), (H) Cañón perteneciente al Fuerte, (I) botones realizados en hueso, (J) fragmentos de pipas de Caolín, con la inscripción "Fiolet $S^{\prime}$ Omer" de origen francés, (K) tapas de aluminio de los frascos de leche, circa 1970, (L) fragmentos de roca que pertenecieron al revestimiento de las fosas del Fuerte, (M) Rocas recuperadas en trabajos previos. Los puntos $\mathrm{A}, \mathrm{K}$, son materiales contemporáneos al siglo XX.

También se efectuaron una serie de sondeos en lugares abiertos, teniendo en cuenta el área correspondiente al fuerte (patios de casas, espacios públicos, antiguas edificios en etapa de demolición). En este proceso se acordó con los vecinos la realización de trabajos de campo en patios de casas de familias. Los sondeos efectuados en el Parque de la Independencia evidenciaron la presencia de restos humanos y artefactos líticos asociados a gres, loza y vidrios de origen europeo. Debemos destacar que los documentos analizados Ratto (2003) dan cuenta de la presencia de los denominados "indios amigos", que a cambio de recursos económicos se encargaban de proteger a la fortificación. Como agenda futura se prevé la am- 
pliación de los trabajos efectuados. Este tipo de registro arqueológico permitirá ampliar la información sobre la interacción de las sociedades de frontera.

\section{Fuerte Blanca Grande}

Fundado en 1828 a orillas de la laguna homónima, a unos $80 \mathrm{~km}$ al Oeste-Noroeste de la ciudad de Olavarría. Un año después fue abandonado por el gobierno quedando en su lugar colonos y grupos originarios asentados en la zona algunos soldados y expedicionarios. En 1869 se lo ocupó nuevamente en forma oficial hasta 1879 (Paladino, 1994). Los restos arqueológicos provienen de las excavaciones realizadas en las diferentes estructuras de basurero ubicadas en la margen interna de la fosa, (Basurero 1 Fosa Oeste) donde se plantearon tres cuadrículas, una trinchera paralela a la fosa Este del Basurero 2 y un sondeo en el Sector Polvorín (Figura 7). También se efectuaron una serie de recolecciones sistemáticas superficiales sobre el perímetro del fuerte y en la zona noroeste que comprende entre la parte posterior del fuerte y la laguna, donde se registró instrumentos líticos, fragmentos de vidrios de las primeras botellas que se introdujeron en la zona de frontera, autopodios de Equus $f$. caballus (caballo) y en menor proporción de Bos p. taurus (vaca), que se encuentran en proceso de análisis (Merlo y Merlo, 2018; Figura 8). El análisis de los vestigios arqueológicos, de los documentos y del paisaje nos brinda información sobre los diferentes actores y momentos de ocupación de la fortificación y el tipo de actividades que se llevaron a cabo en ese espacio. Tanto en la documentación como en el registro arqueológico se evidencian la interacción entre comunidades originarias y los eurocriollos que ocuparon la fortificación.

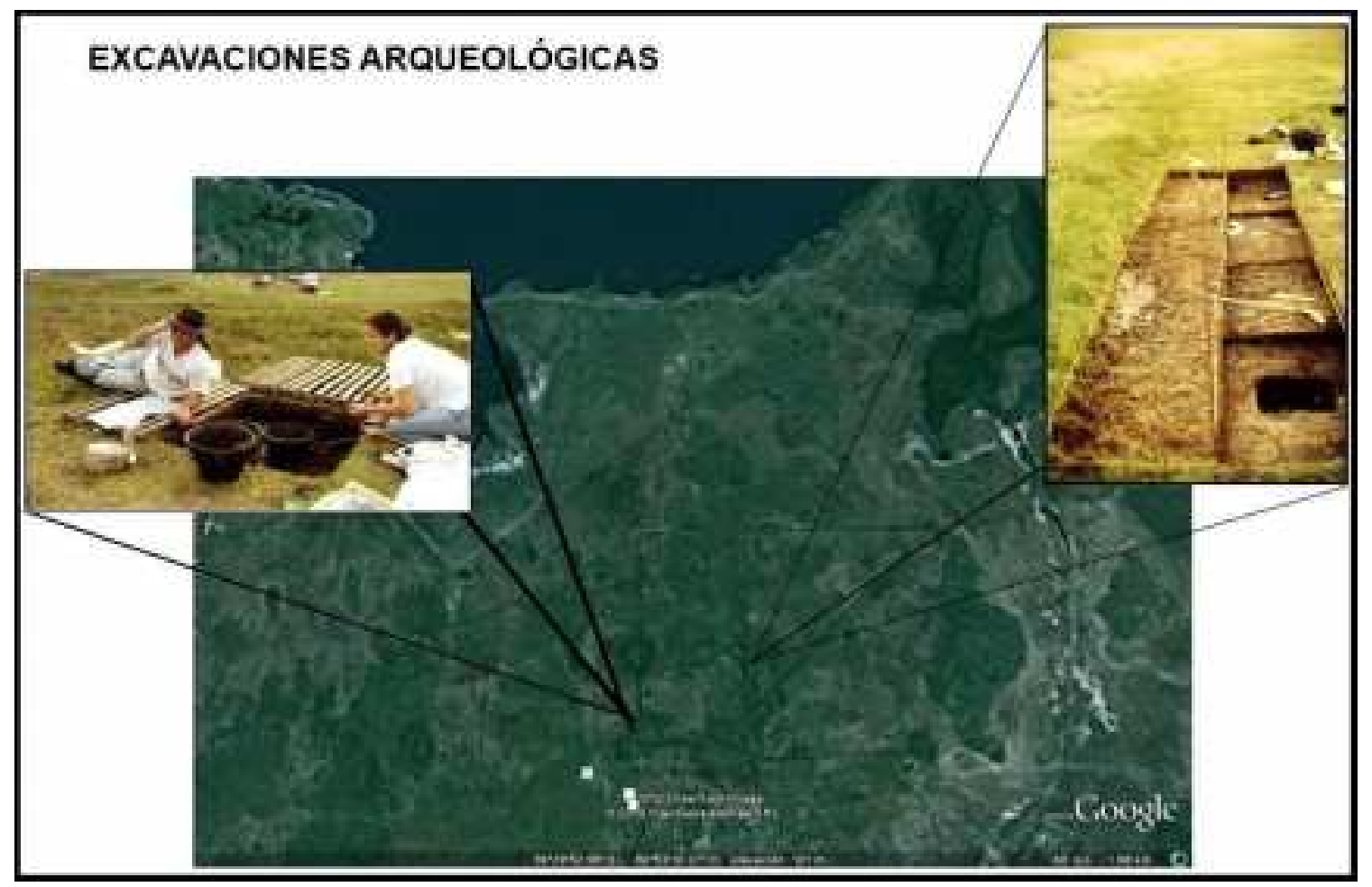

Figura 7. Imagen satelital del Fuerte Blanca Grande Google earth, con la ubicación de las áreas excavadas, Olavarría. (Extraído de Merlo, 2014:94). 


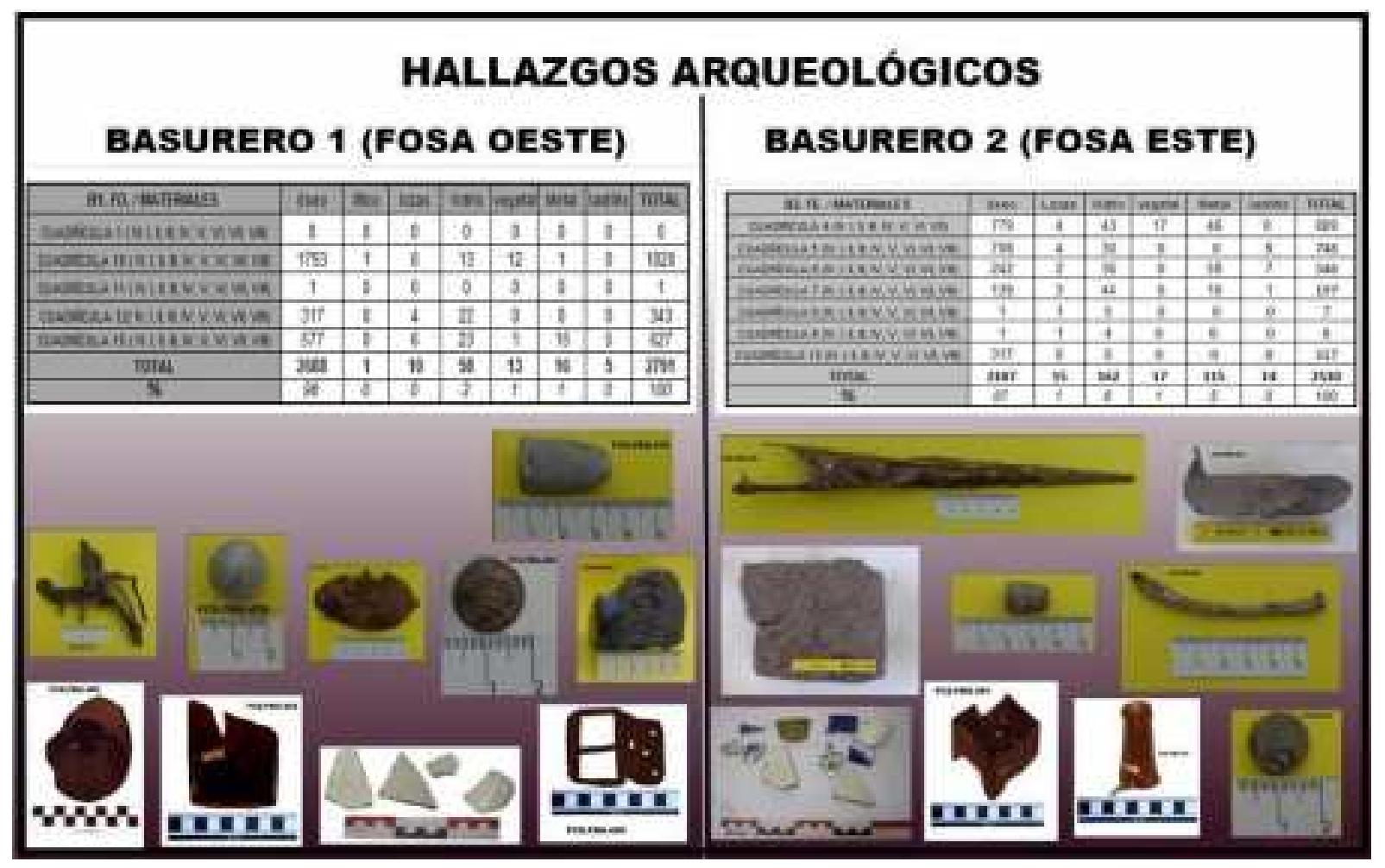

Figura 8. Materiales recuperados en las excavaciones efectuadas en la zona de basureros del Fuerte Blanca Grande: elementos óseos (huesos y dientes de diversos animales), vidrios, metales, vegetales, lozas, ladrillos, líticos y fragmentos de carbonato de calcio.

\section{Fortín La Parva}

Ubicado a $10 \mathrm{~km}$ del arroyo de Las Flores, en General Alvear. El jefe de la Frontera Sur, coronel Ignacio Rivas, solicita al gobierno establecer un fuerte en el "Médano de la Parva" ya que los dos últimos malones hacia el Saladillo habían entrado por dicho lugar. Su construcción fue autorizada el 7 de octubre de 1858. De acuerdo con los documentos escritos consultados en el Archivo del Juzgado de Paz de Saladillo, ([AJPS] Carta de vecinos al Juez de Paz de Saladillo, S/N, de septiembre de 1858), los habitantes de la zona, interesados en su propia protección y seguridad, donaron los ladrillos para la construcción del fortín. Allí se realizaron recolecciones superficiales a través de ocho transectas paralelas a los fosos en campo arado, se excavaron 10 cuadrículas en el montículo central y dos en el lado interno de la fosa Noreste del fortín y se realizaron tres sondeos, sobre la barranca interna de la fosa del montículo secundario en el sector Noreste, donde se registraron hallazgos superficiales (Figura 9). Dada la densidad de los elementos hallados, se lo denominó sector de descarte y se procedió a excavar seis cuadrículas en dirección Oeste-Este, recuperándose una alta concentración de restos óseos y artefactos arqueológicos de origen europeo (Figura 10). 


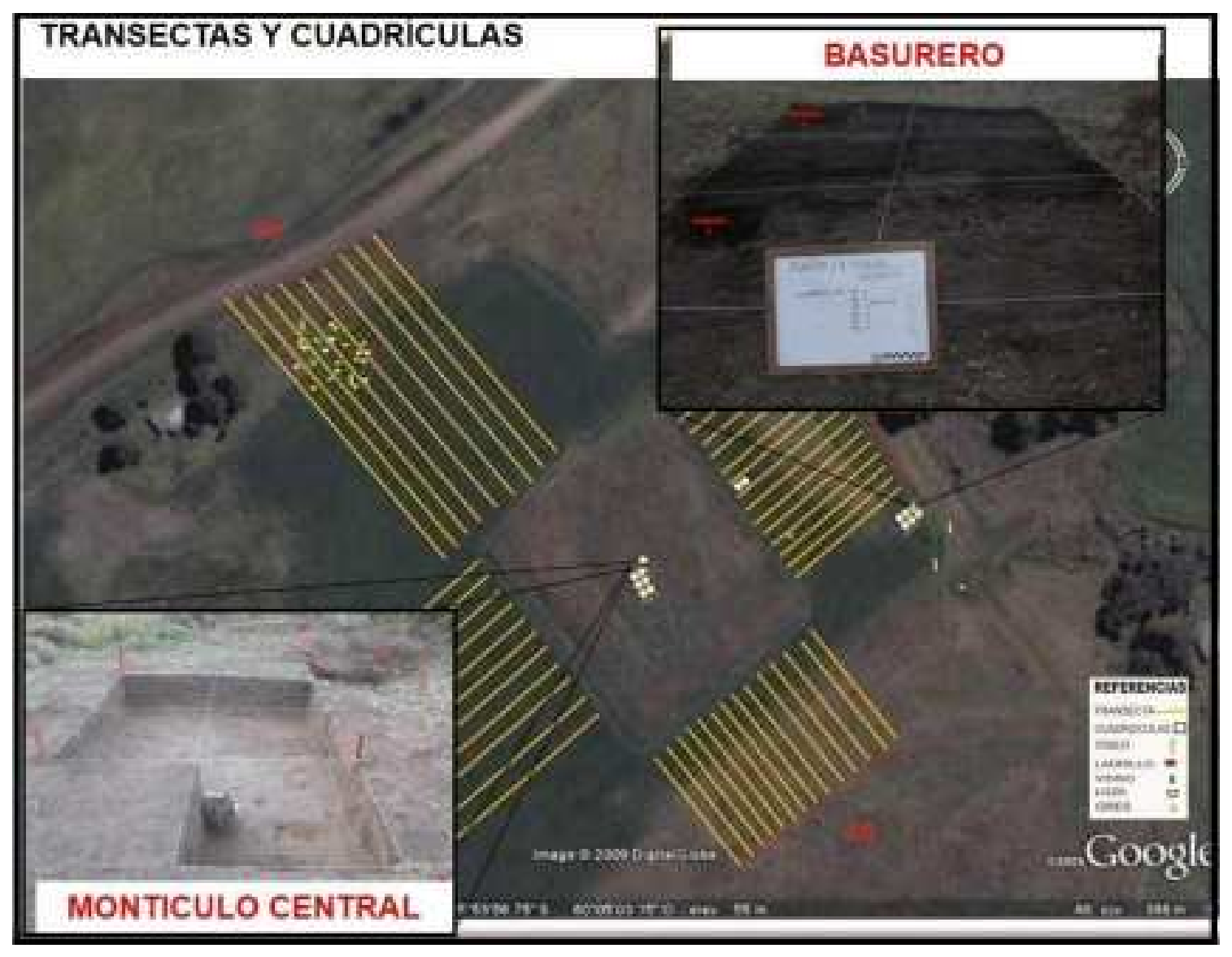

Figura 9. Áreas relevadas del Fortín La Parva desde 1997.

En marzo de 1857, el Dr. Alsina asumió como gobernador de Buenos Aires y promulgó la ley 1867, a fin de efectivizar la mensura de los ejidos en partidos rurales y la venta de terrenos fiscales ocupados por estancieros que, en teoría, arrendaban al estado, prohibiendo la renovación de este tipo de contratos. Paralelamente, se buscó hacer efectiva la presencia estatal en la frontera y se designaron tierras para asentamientos de varias tribus de "indios amigos", en combinación con el sistema de fortines.

En 1858 los grupos nativos aliados a Urquiza atacaron la zona del FLP, registrado por un documento, donde se redactan las declaraciones del dueño de la pulpería como testigo de dicho malón:

\section{Declaración del Testigo Dn Robert}

continuo compareció el duodecimo testigo a quien previo juramento de ordenanza lefue preguntado su nombre ejercicio si tenía casa de trato en Arebalo [FLP], si esta fue saqueada por los indios y en tal caso que cantidad de vevida tenía espesificamente cual fuese, dijo, llamarse Dn Agustin Robert de ejercicio negociante; que la casa de negoció que tenía en el Fortin Arebalo fuera del Foso fue saqueada y quemada por los indios en los días dies y seis y dies y siete de Marzo ppdo que el no se halló presente... queno tiene mas que decir que lo dicho es la verdad a cargo del juramento hecho enlo que se afirma y ratifico leyda y fue esta la declaración y dijo ser de edad de 31 año y la firma con el Sr. Fiscal y presente 
Teoría y Práctica de la Arqueología Histórica Latinoamericana

Año X, Volumen 12 | 2021 / ISSN en línea: 2591-2801 | ISSN versión impresa: 2250-866X

Secretario. Agustin Robert

Antemi Enrique Stablo Vilinario de Burdun Acto=

(Expediente Fortín Arévalo, 1859, en Langiano y Schwartz, 2006:167).

En este malón, tomaron como rehén al Coronel Arévalo, pidieron la rendición de la tropa e incendiaron el puesto fortificado recientemente instalado. Entonces, tropas del Saladillo, del Fuerte Esperanza y del Azul acudieron en ayuda de los fortineros. Pero el conflicto se agudizó y Calfucurá atacó Bahía Blanca, Azul, Tandil y nuevamente a la población de 25 de Mayo. En octubre de 1859, Ignacio Rivas se reunió en el FLP con los caciques Catriel y Cachul, a los efectos de concretar un tratado en momentos cercanos a la Batalla de Cepeda (donde, cabe recordar, las fuerzas de Buenos Aires fueron derrotadas por las de la Confederación; Barros, 1975:20 [1872]).

Las recolecciones de superficie en la zona arada realizadas mediante transectas reportaron la presencia de numerosos artefactos, tales como vidrios, gres, lozas y una importante concentración de fragmentos de ladrillos y restos faunísticos. En la Transecta No, sobre los sectores externos a la estructura castrense se recuperó la mayor concentración de materiales arqueológicos, hecho que podría asociarse a la presencia de una pulpería cercana al fortín, según refieren documentos escritos de la época, presentado anteriormente.

Dentro del montículo central se registraron numerosos fragmentos de ladrillos dispersos, en superficie y estratigrafía. También se detectaron cimientos de ladrillo y adobe $(\mathrm{C}=9$ y 10$)$, que podrían corresponder a las viviendas y ranchos de la guarnición militar. En ese sector se hallaron fragmentos de metales, carbón vegetal, huesos quemados y trozos de cuero. La fauna aquí recuperada, fueron identificados como Bos p. taurus, Ovis o. aries (Oveja), Chaetophractus villosus (Peludo), Dasypus hybridus (Mulita) y una escasa cantidad de huesos de ave. Es de importancia resaltar la presencia de Ovis o. aries en similares proporciones que Bos p. taurus y la falta de registro de la primera en el sector de descarte. Teniendo en cuenta, que para el período de construcción y fundación del FLP (1852 a 1858), su ubicación a $120 \mathrm{~km}$ aproximados al Sur del río Salado; momentos donde comienza a desarrollarse la producción masiva de esta especie en estancias cercanas a la ciudad de Buenos Aires, norte del río Salado (Zeberio, 2001; Barsky y Djenderedjian, 2003). La falta de desarrollo de cercos perimetrales para el control de este tipo de ganado retrasó el desarrollo de este tipo de recurso.

La fosa perimetral del montículo secundario del fortín presenta las características de una zona destinada al descarte, se recuperó una gran concentración de material óseo mezclado materiales de origen cultural. Este conjunto arqueofaunístico está integrado por miles de fragmentos óseos alterados térmicamente pertenecientes a Bos p. taurus y, en menor proporción, a Equus f. caballus, Dasypus hybridus, Chaetophractus villosus y Ozotoceros $b$. celer. Las unidades anatómicas que representan a cada taxón son los huesos largos y las falanges de la primera especie son las que predominan y en su mayoría no registran alteración térmica intensa. Los huesos largos exhiben los grados más altos de alteración térmica (totalmente quemado y calcinado) y se hallan muy fragmentados, al igual que las epífisis proximales y dístales de las unidades anatómicas superiores. Se ha registrado un gran número de placas dérmicas de armadillos, calcinadas, quemadas y algunas sin quemar, mientras que los huesos del esqueleto aparecen en bajas proporciones y, en su mayoría, quemados. Los huesos de venado poseen una baja representatividad y evidencias leves de alteración térmica. Es importante resaltar que en el conjunto presentan distintos grados de alteración térmica y huellas antrópicas (Merlo, 2015).

La ausencia de elementos óseos de Ovis o. aries, los datos históricos anteriormente mencionados, el registro de miles de fragmentos óseo alterados térmicamente de Bos p. taurus en el área de basurero 
estarían dando indicios que el registro arqueofaunístico de este sector representa momentos previos a la fundación del fortín (1858). En cambio, la presencia de Ovis o. aries en las excavaciones efectuadas en el montículo central y sus fosas perimetrales en similares proporciones que Bos p. taurus podría ser atribuidas a momentos posteriores a la fundación del mismo.

El análisis de los materiales arqueológicos, la lectura de fuentes documentales y los estudios actualísticos, han permitido establecer comparaciones que aportan datos sobre la formación de los depósitos en el área de descarte. Los trabajos de experimentación realizados en el año 2006, con el objeto de comprobar si con huesos de Bos p. taurus actuales en estado fresco y seco, vegetación autóctona seca, sebo y guano se podía generar suficiente combustión para cocinar piezas de alfarería. En este trabajo experimental se registró el grado de alteración que sufren los huesos secos, frescos y frescos con carne al ser sometidos al fuego: La experiencia se realizó a cielo abierto en tres fogones: $\mathrm{F} 1=$ huesos secos; F2= huesos secos y frescos; F3= huesos frescos con carne (ver Langiano et al., 2006). Como resultado de esta experiencia se determinaron huesos calcinados, quemados, parcialmente quemados y sin quemar. La temperatura para la cocción completa de la cerámica es de $800^{\circ} \mathrm{c}$, similar a las temperaturas que se deben alcanzar para fundir adecuadamente ladrillos realizados en adobe (Higueras y Oyarzun, 2010).

Los trabajos de experimentación y el análisis del registro arqueológico permiten establecer valiosos parámetros comparativos. Debe recordarse que en la zona donde se ubica el FLP no hay rocas o concreciones calcáreas aptas para ser utilizadas con un fin constructivo. En el documento del "Juez de Paz de Saladillo, del 16 de junio de 1852" dirigido al "Señor Ministro de Guerra y Marina Don Dr. Pastor Obligado" se menciona la contratación de dos albañiles italianos para fabricar 100.000 ladrillos con las que construyeron las instalaciones del fortín. Pero el documento no menciona con qué combustible debían ser cocinados tales ladrillos ni dónde. El ambiente donde se construyó el FLP se caracteriza por la ausencia de árboles para obtener elementos de combustión (leña) con este fin; a ello debe sumarse la escasa capacidad y los inadecuados caminos para el transporte de madera desde los centros naturales de abastecimiento (Merlo, 1999), así como la dificultad para trasladar materiales con fines constructivos. Es posible que los restos óseos, conjuntamente con otros elementos de origen animal (e.g. como sebo y guano), hayan sido utilizados como elemento de combustión para la cocción de los ladrillos. El uso de los huesos para hacer fuego explicaría que en el registro arqueológico se encuentren elementos óseos con una significativa alteración térmica, destacándose el elevado grado de calcinamiento y en menor proporción huesos quemados y parcialmente quemados (Merlo, 1997, 1999, 2006, 2007, 2014, 2015; Merlo et al., 2008) y afirmando la posibilidad de confeccionar fogones con material óseo para la cocción de cerámicas que fue desarrollada experimentalmente (Langiano, 2006).

Las investigaciones desarrolladas hasta el momento indicarían que el área de descarte del fortín (sector basural) se formó a partir de la depositación constante de los desechos de los fogones empleados para el cocinado de los ladrillos para la construcción del fortín (1852 a 1858). En esta práctica se utilizaron huesos de Bos p. taurus y ocasionalmente huesos de Equus f. caballus, Ozotocero b. celer, Dasypus hybridus y Chaetophractus villosus. Hasta el momento no se ha logrado ubicar a los fogones u hornos donde se pudieron realizar estas actividades.

Sobre la base de los resultados obtenidos hasta el momento, se han planteado distintos usos espaciales para el interior y el exterior del FLP a partir de los efectos identificados en los elementos óseos recuperados en los diferentes sectores trabajados, la comparación y distribución general del registro arqueológico y las fuentes documentales consultadas (Figura 10). 


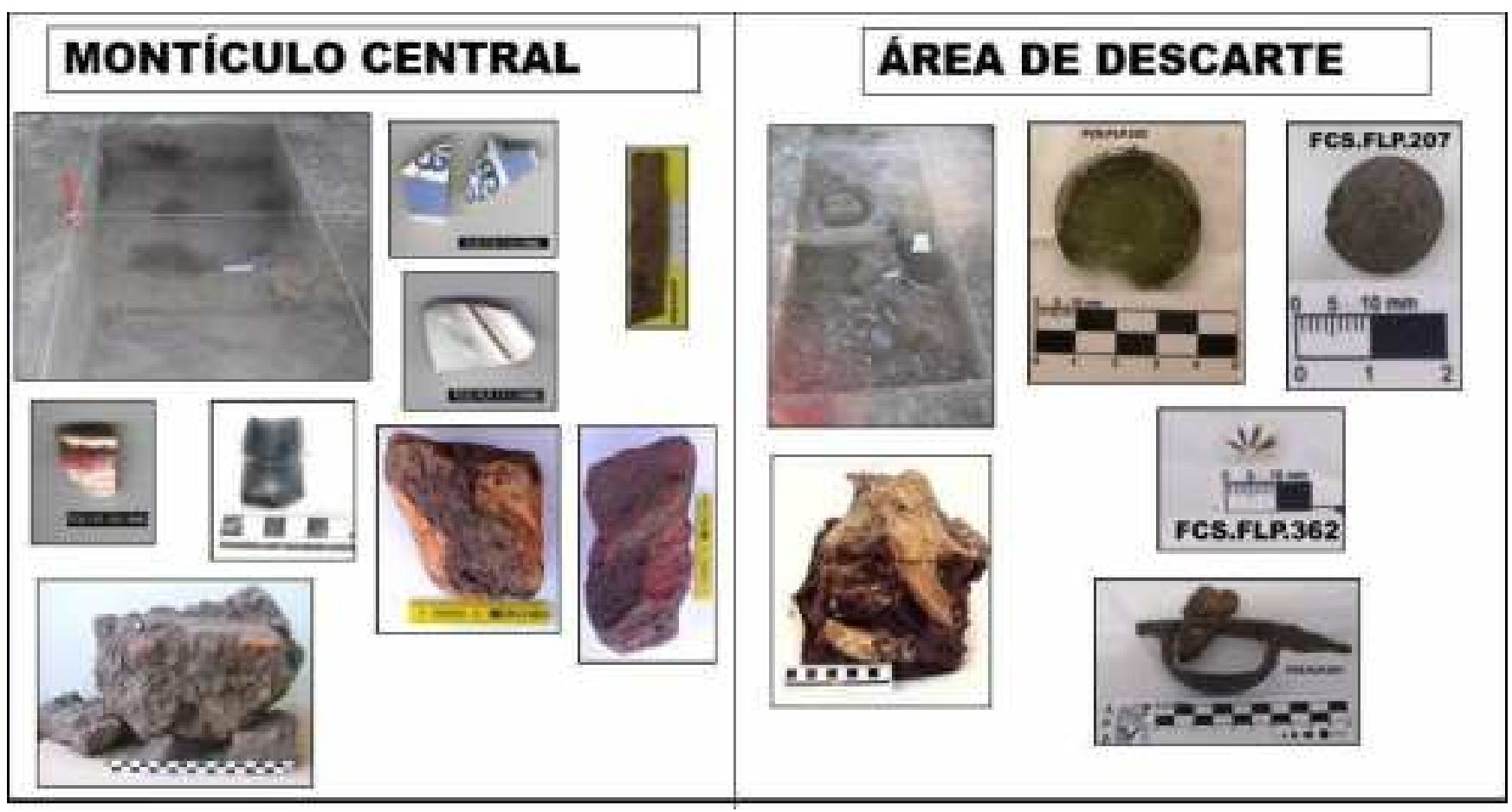

Figura 10. Materiales recuperados en las excavaciones del Fortín La Parva: en el montículo central se recuperó gran cantidad de materiales: huesos, fragmentos de lozas, gres vidrios, metales y ladrillos, así como restos vegetales y material lítico. La muestra de fauna analizada está constituida por especies domésticas (vacunos y ovinos). La fauna autóctona está representada por restos óseos de mulita y un hueso de ave. Sólo se observaron huellas de procesamiento en los huesos de vaca y oveja

(Merlo, 2015).

\section{Localidad Arqueológica El Perdido}

Ubicada en Olavarría, en la cuenca de drenaje del Arroyo El Perdido-Tapalqué en su curso superior, en el sector Noroeste del cordón serrano de Tandilia. El lugar presenta un relieve muy suave, constituyendo un paisaje de llanura generalizado, con ondulaciones que integran divisorias subordinadas, líneas de drenaje y depresiones. Un importante desarrollo de bañados, lagunas transitorias y permanentes de uno a tres $\mathrm{km}$ de diámetro promedio, caracterizan el sector de cabeceras de la cuenca. La Mensura $\mathrm{N}^{\circ} 41$ del Archivo General de Geodesia del Ministerio de Obras Públicas de la Provincia de Buenos Aires, ubica al fortín El Perdido en 1865, bajo el mando de Álvaro Barros (Thill y Pueidemonech, 2003).

Las investigaciones arqueológicas comprendieron prospecciones, recolecciones superficiales sistemáticas, sondeos y excavaciones en el Fortín El Perdido se excavaron cuatro cuadrículas en el foso, una en el montículo secundario, seis en el montículo principal y dos en la Lomada 1, ubicada a $3 \mathrm{~km}$ en línea recta del fortín y a $50 \mathrm{~m}$ del arroyo El Perdido, recuperándose una gran cantidad de artefactos arqueológicos de procedencia europea (botellas de vidrios de bebidas alcohólicas y medicamentos, armas de fuego, balas de plomo, botones militares, entre otros metales; lozas botones de nácar, instrumentos líticos: como puntas de flecha, raspadores raederas, cuchillos confeccionados con ftanita. Cabe destacar la presencia de instrumentos, como cuchillos y raspadores tallados en vidrio que implicaría la interacción 
entre eurocriollos e indígenas, Estos hallazgos fueron realizados tanto en recolecciones superficiales como en las excavaciones dentro fortín y en zonas cercanas. Además se localizaron instrumentos indígenas y desechos de su procesamiento, junto con material de origen europeo en cinco lomadas naturales y asentamientos de colonos en siete taperas (Figura 11 y 12).

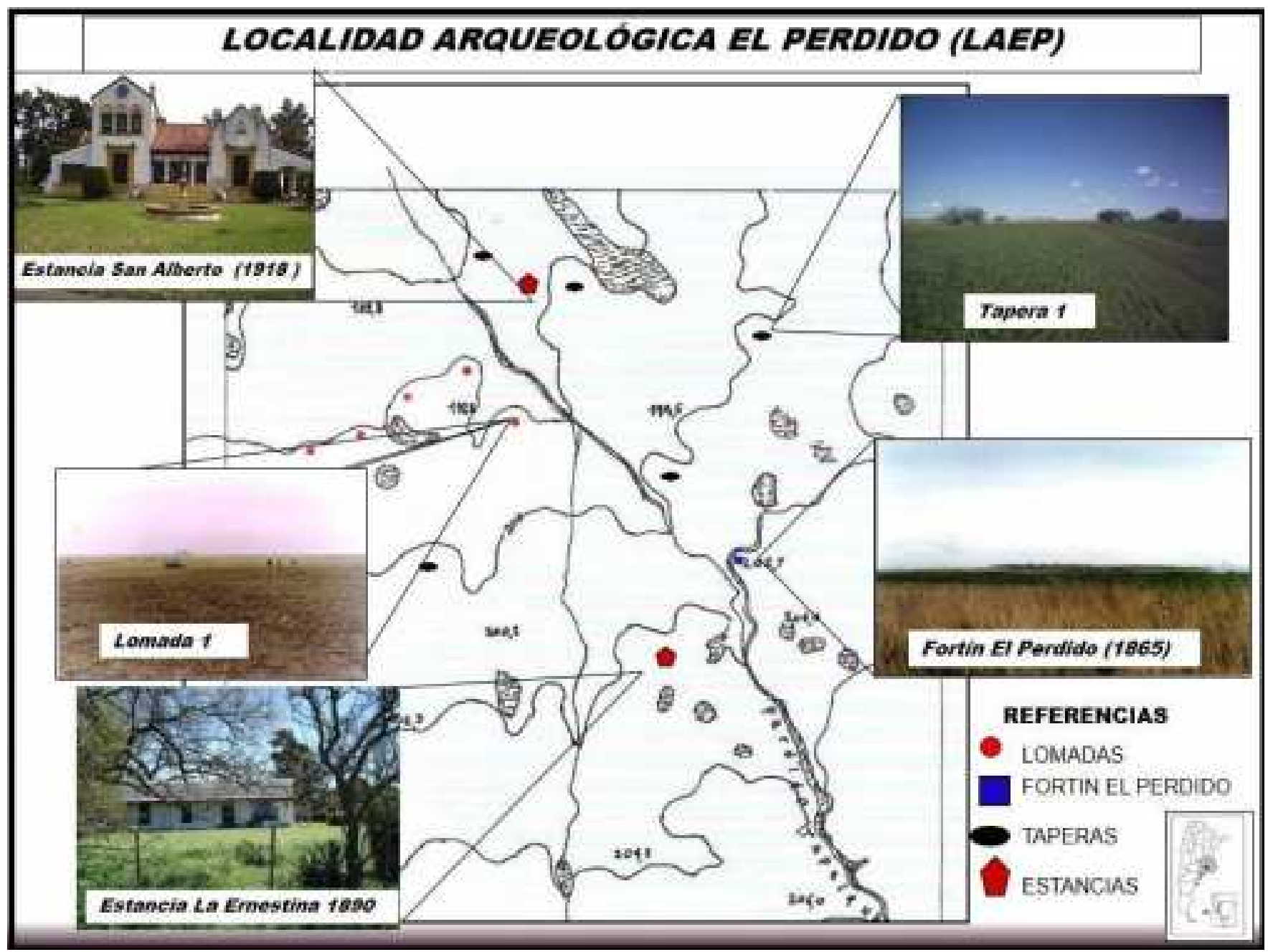

Figura 11. Áreas arqueológicas relevadas desde 1996 a la actualidad de donde provienen los materiales arqueológicos analizados. (Extraído de Merlo, 2014:161). 


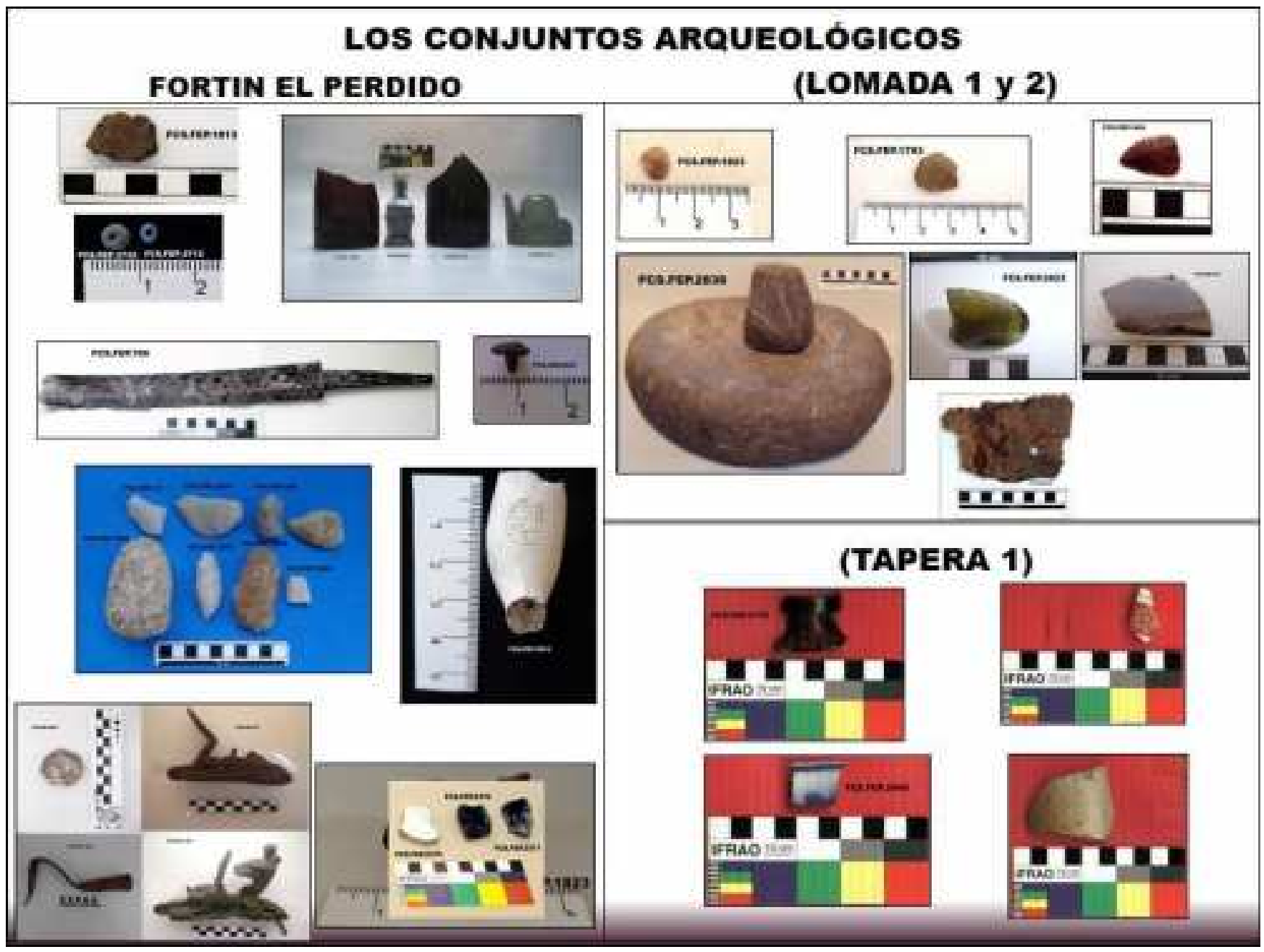

Figura 12. Fortín El Perdido: (A) chaquiras de cinturones que usaban las mujeres indias, (B) cerámica india, (C) instrumentos líticos que usaban los indios, (D) fragmento de sable (E) tachuela de tapizado de carreta, (F) fragmento de vidrio tallado como instrumento indio, (G) fragmento de la cazuela de pipa de caolín, $(\mathrm{H})$ botellas sopladas y moldeadas; frascos de medicamentos o perfume, (I) bala de plomo, fragmentos de armas cortas y largas, del sistema de avancarga, con mecanismos de percusión de fusil, uno de los cuales tenía la piedra de pedernal incorporada. Lomada 1 y 2: (A) raspador lítico, (B) cerámica india, (C) punta de flecha en aftanita roja, (D) mortero con mano de moler, (E) fragmento de vidrio tallado como cuchillo, $(F)$ raspador indio en vidrio, $(\mathrm{G})$ lozas y vidrios, $(\mathrm{H})$ fragmento de chapón. Tapera 1: (A) fragmento de pico de botella, $(B, C)$ loza europea, (D) gres de porrón de cerveza de fines del siglo XIX. 


\section{Fuerte Lavalle}

Está ubicado en la intersección del Arroyo San Quilco con el "Camino de los Indios a Salinas". El viajero Armaignac (1974 [1883]) lo menciona como el más importante de toda la frontera de Buenos Aires desde el punto de vista estratégico.

Actualmente sus estructuras arquitectónicas están desdibujadas por el intenso trabajo agrícola y por la construcción de un camino vecinal, por lo que no se puede ver claramente el trazado de los fosos (Figura 13). Las tareas de recolección superficial sistemática se efectuaron por medio de 10 transectas paralelas al alambrado, en el campo arado $(n=130)$ y en cuatro cuadrículas donde se registró presencia de material cerámico, gres, loza, metal, óseo y vidrio ( $\mathrm{n}=189$; Figura 14). En cuanto a los vítreos es importante destacar la presencia de raspadores confeccionados en ese material. Tanto en el Fuerte Lavalle como en la Localidad Arqueológica El Perdido, las evidencias de confección de artefactos con técnicas indígenas, similares a las realizadas con el material lítico, en fragmentos de botellas de vidrios indican una clara interacción entre los eurocriollos y las comunidades originarias. A esto se le debe agregar que estos artefactos en su mayoría fueron encontrados en la superficie de las fortificaciones y la evidencia de la cartografía destaca la presencia de "indios amigos".

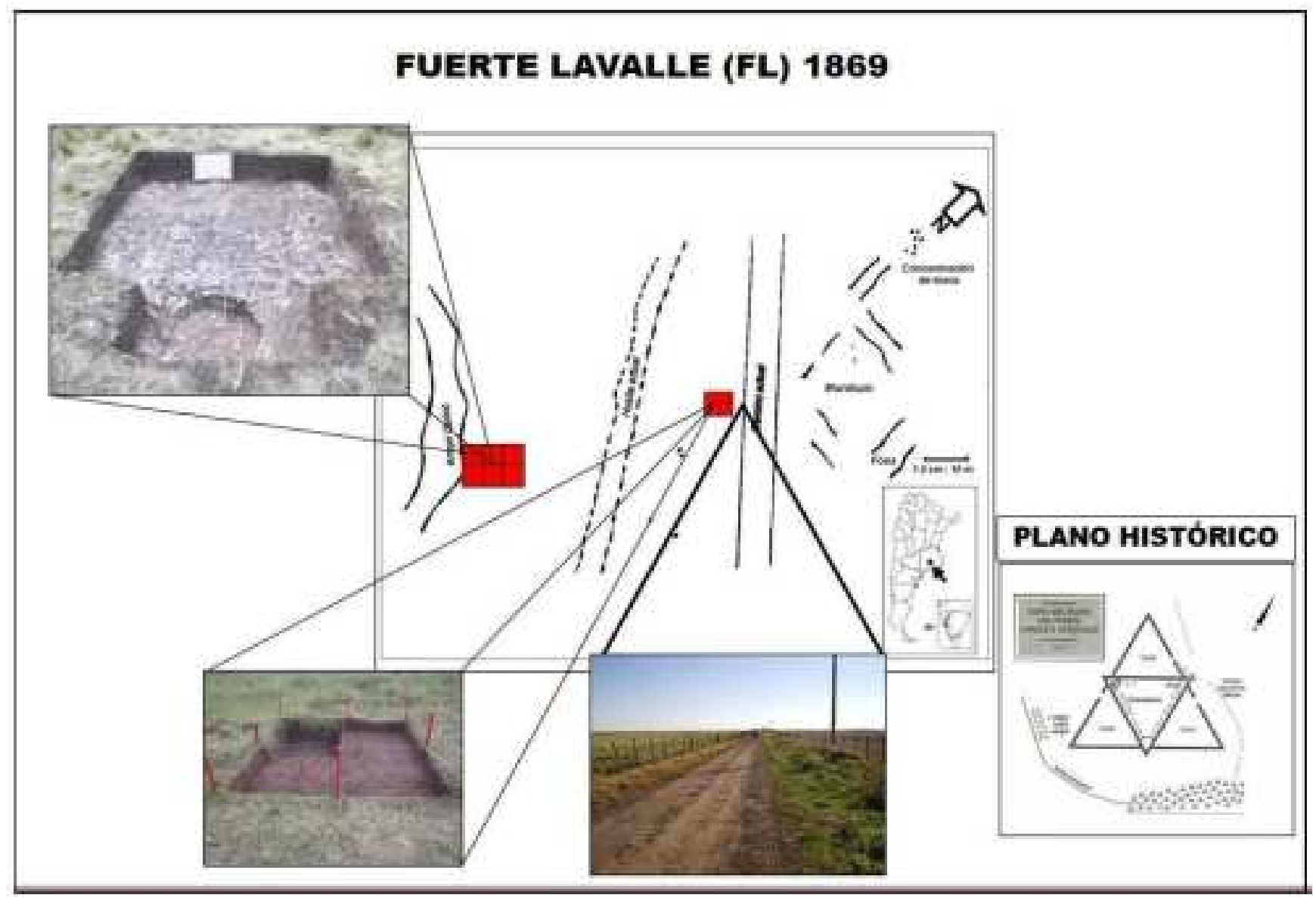

Figura 13. Excavaciones realizadas al costado del camino en el año 2008 y sobre el suelo no roturado en el año 2000. 


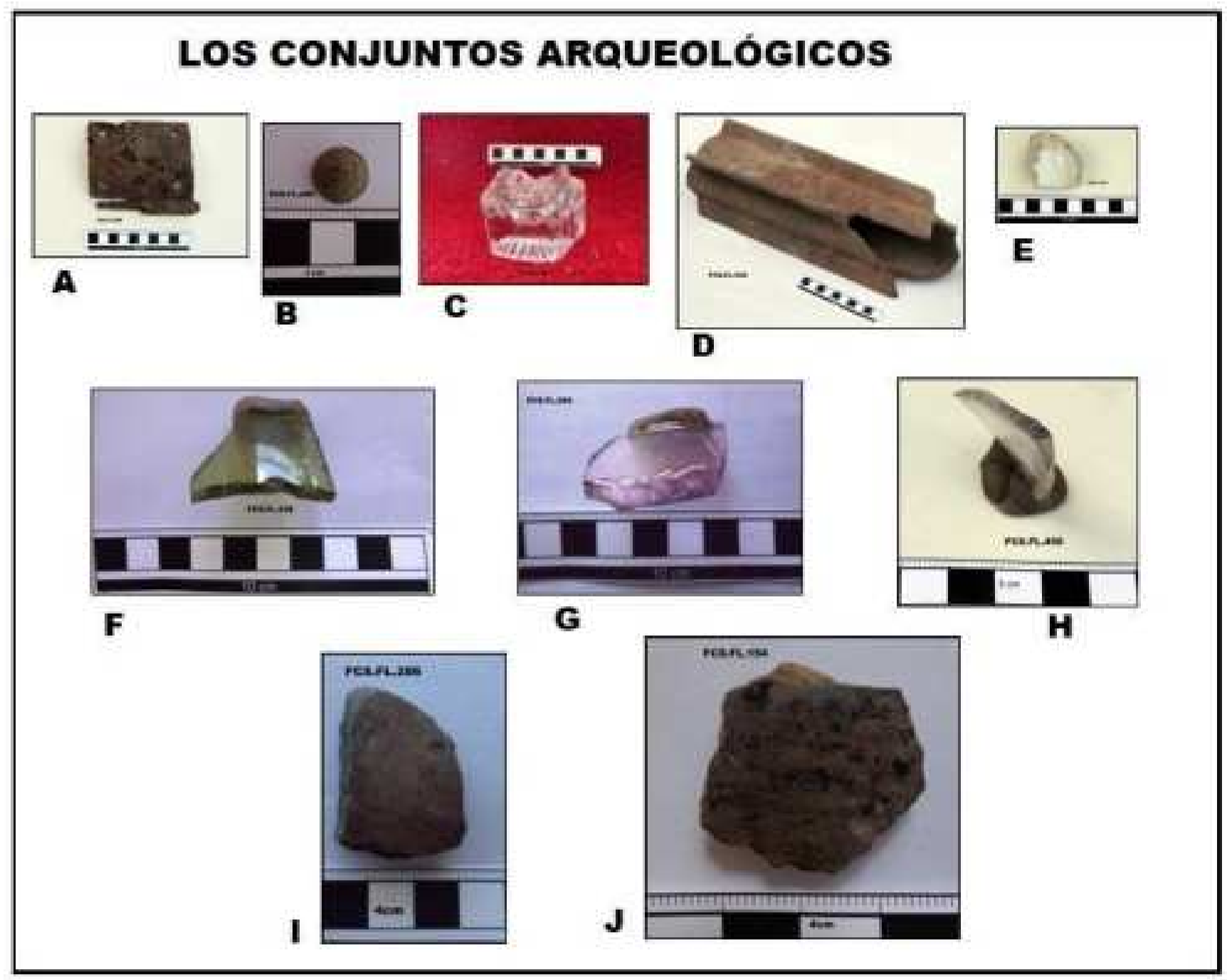

Figura 14. Hallazgos arqueológicos más destacados: (A) bisagras, (B) botón con el escudo argentino, (C) fragmentos de vasos de vidrio, (D) cilindro de fundición base de poste de telégrafo. (E) fragmentos de aisladores de porcelana de telégrafo, (F, G, H) Fragmentos de botellas tallados como raspadores

líticos; estos instrumentos en vidrio aportan claras evidencias de intercambio entre los pueblos originarios y la sociedad eurocriolla, (I, J) fragmento de cerámica indígena con incisiones.

\section{Fuerte San Martín}

Está en el partido de Coronel Suárez y se encuentra rodeado por el arroyo Sauce Corto y uno de sus afluentes, vertiente del Sistema serrano de Ventania. Se localiza a $25 \mathrm{~km}$ de la ruta entre Coronel Suárez y San Eloy, hacia la sierra (Abra de los Hinojos). En marzo de 1872, se trasladó la guarnición que estaba en el Fuerte Belgrano o Pillahuincó Grande al arroyo Sauce Corto, con el nombre de General San Martín. Era un sitio fortificado sobre las horquetas formadas por dicho arroyo y el arroyo San Antonio, que encerraba un área de $600 \mathrm{~m}^{2}$ (Thill y Puigdomenech, 2003). 
En la actualidad se ha detectado un basural en la barranca Sur-Este del arroyo Sauce Corto, que sugiere un uso del espacio orientado al descarte de desperdicios o de restos materiales por parte de los pobladores del fuerte. Se registró la distribución espacial de los restos arqueológicos del basural y se analizaron los procesos de formación del sitio (i.e. perturbación por agentes biológicos, como el pisoteo de animales, procesos geológicos y geomorfológicos, como las periódicas inundaciones del arroyo). Se efectuaron recolecciones superficiales mediante el trazado de 10 transectas paralelas, perpendiculares al curso de agua en todo el perímetro del sector descarte del fuerte y se excavaron dos cuadrículas en la margen superior derecha del área. Se ha localizado otro basural en la barranca del arroyo Sauce Corto, donde se pudo detectar una mayor presencia de fragmentos de vidrio, restos óseos objetos de metal y restos vegetales, así como una escasa presencia de fragmentos de gres y loza, cerámica indígena, botones y un fragmento de pipa de caolín. Arqueológicamente no se evidenciaron artefactos de procedencia local, pero la cartografía registra presencia de "indios amigos".

\section{Discusión y conclusiones}

Los relevamientos documentales y los trabajos arqueológicos permitieron establecer que los puestos fortificados de principios de siglo XIX debieron prever estrategias de subsistencia para hacer frente a las condiciones ambientales adversas, que les permitieran perdurar en el tiempo, o la construcción de las edificaciones sobre las cotas de altura elevada, para evitar inundaciones ocasionadas por las frecuentes crecidas de lagunas, ríos y arroyos. Los habitantes de esos sitios fortificados debieron recurrir, en sus inicios, a una mayor explotación de los recursos naturales disponibles localmente, como fuentes hídricas, vegetales y faunísticos. También el intercambio comercial y pacifico con las poblaciones originarias fue un proceso sistemático que se fue fortaleciendo en el tiempo, con presencias de algunos episodios de crisis ante el incumplimiento de tratados por parte del incipiente estado nacional. Un ejemplo de esto es el comercio de la sal, recurso mineral indispensable para la conservación de la carne y el procesamiento de los elementos de cuero. La sal que abastecía a Buenos Aires (norte del Río Salado), provenía de Salinas Grandes y la producción estaba a cargo de los indígenas. Así, por ejemplo, en 1810, el Coronel Pedro Andrés García, durante su viaje a Salinas, con el objetivo de proveer sal a la población de Buenos Aires, debía solicitar permisos para introducirse en su territorio, ofreciéndoles regalos, como forma de cortesía para permitirles el paso. Estas negociaciones debían ser renovadas cada año, eran una de las tareas más ingratas del gobierno de Buenos Aires, cuya autoridad no era reconocida por las comunidades originarias y debían realizarlas personas capaces de negociar. Este fue el caso del Coronel García que en el parte diario manifestaba que:

“...mandé al cacique Victoriano..., manifestándole que la expedición venía á cargar de sal, como lo acostumbrábamos á hacer de paz y buena amistad que él estaba cierto. de ello·, y se mantenía en mi compañía para hacerlo entender á todos los indios; y para oponerse con sus gentes y armas, si alguno tenía el desconocimiento de injuriar la expedición, ni ofenderla en lo más leve y que así se lo hiciese entender á los caciques que lo mandaban, si no querían como amigos venir á tratar ..." (García, 1974 [1836]:73).

Las diferentes comunidades nativas acostumbraban a intercambiar recursos, información, pasos por arroyos y lugares, etc. por elementos elaborados (e.g. cuencos, platos, cuchillos, etc.), bebidas alcohólicas, azúcar, tabaco, yerba, medicamentos etc. Las situaciones conflictivas aparecían cuando no se cumplía con la palabra pactada o por situaciones de maltrato hacia algún miembro de la comunidad, 
sólo se apelaba a la guerra cuando no quedaba otra opción pacífica. En otras palabras, mantener relaciones hostiles con las comunidades originarias dificulta la supervivencia en la frontera y la posibilidad de avanzar en tierra adentro, teniendo en cuenta las limitaciones existentes para el traslado de recursos desde otros centros de abastecimiento como el puerto de Buenos Aires, las variaciones climáticas de la región pampeana y la falta de árboles para poder generar fuego con elementos alternativos para la cocción de alimentos y para calentarse ante las bajas temperaturas del invierno (Merlo, 2014).

A partir de mediados de la década de 1850, los conflictos políticos y sociales en la frontera bonaerense en el marco de las disputas entre el Estado de Buenos Aires y la Confederación Argentina generaron un incremento en la fricción de las relaciones interétnicas en la zona del "Camino de los Chilenos" (actual centro de la provincia de Buenos Aires) por diversas razones. El incipiente Estado unificado a partir de 1862 basó su poder en el control de los factores productivos al aumentar su dominación sobre los restantes sectores sociales, especialmente sobre los grupos originarios, estableciendo las llamadas líneas de fronteras interiores que delimitaban jurisdicciones. Así se dividió racionalmente el territorio indígena y se cambiaron las denominaciones de accidentes geográficos (topónimos, Figura 15), destruyendo lugares percibidos como prohibidos o como aptos para ser habitados, para actividades de recolección y de caza para las poblaciones originarias. Los eurocriollos sin recursos pasaron de tener su producción para la subsistencia, a ser puesteros de los terratenientes o a transformarse en "gauchos" errantes similar al personaje Martín Fierro.

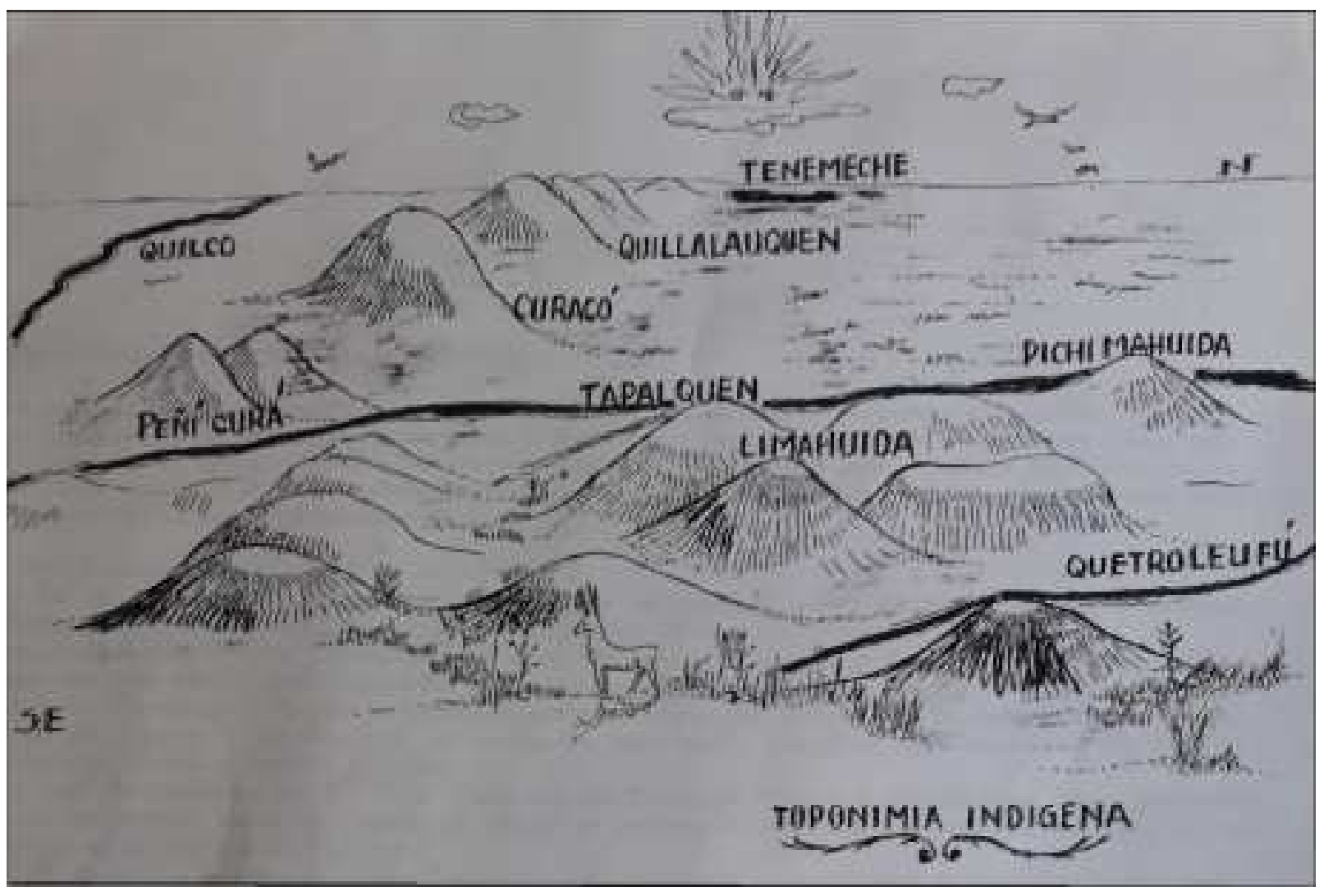

Figura 15. Toponimia en idioma mapudungun (Mapuche) de lugares geográficos del Partido de Olavarría, provincia de Buenos Aires. Dibujo realizado por Gustavo Monforte. 
Los datos aportados por las fuentes documentales, la cartografía de la época, las fotografías y la información obtenida mediante las investigaciones arqueológicas que se desarrollaron en los fuertes Independencia, Blanca Grande, San Martín y Lavalle y los fortines La Parva, Arroyo Corto y la Localidad Arqueológica El Perdido, dan cuenta acerca del lugar estratégico que ocupan estos sitios para el dominio de las comunidades originarias, los colonos e inmigrantes.

En esta compleja frontera del siglo XIX comprender el panorama de ocupación del espacio, tanto por parte de los grupos originarios como de otros actores sociales, amalgamado con cuestiones de género y de poder hacen más compleja la relación entre los documentos y el registro arqueológico (Langiano, 2015). Los documentos escritos permiten plantear un complejo sistema de relaciones interétnicas que, en un primer momento, fue un intercambio más acordado entre eurocriollos y los grupos originarios (i.e. la primera ocupación de los Fuertes Independencia y Blanca Grande). A medida que aumentaba la población en la frontera, las relaciones entre los diferentes actores se incrementa la interacción para el intercambio de productos y relaciones sociales pacíficas y conflictivas, con momentos de alta fricción, estableciéndose relaciones más asimétricas (i.e. Localidad Arqueológica El Perdido, Fuerte Lavalle y Fortín La Parva) y un mayor control del espacio aborigen y el reemplazo de los recursos naturales por los introducidos en la región. En esta época se incrementó el ingreso de materiales foráneos, importados desde Europa, tales como vidrios, cerámicas, metales, lozas y gres, que entraban al país por el puerto de Buenos Aires para ser distribuidos al interior. La presencia de variabilidad de recipientes de vidrio en la Localidad Arqueológica El Perdido y la alta diversidad de colores del gres cerámico presente en el Fortín La Parva, daría algunos indicios sobre la cantidad y multifuncionalidad de los recipientes utilizados en la frontera. Lo anterior, además, estaría demostrando variadas relaciones de intercambio, circulación de bienes y la presencia de comerciantes o de pulperías. En cuanto al color de los vidrios, se puede afirmar que existe una cierta similitud entre los recuperados en el Fuerte Lavalle y el Fortín La Parva, mientras que en el Fuerte San Martín se observa más diversidad de colores. Las lozas del Fortín La Parva y el Fuerte Lavalle tienen las características de los objetos que se usaban en los puestos de campaña o fronterizos, mientras que en los fuertes Independencia y San Martín son del tipo “ [...] para recibir o para demostrar poder”. (Schávelzon, 1991).

En la pampa Argentina de fines del siglo XIX en las pulperías se reunían diversos actores y sectores socio-étnicos (Gómez Romero, 2002). En esta misma época, se importan variadas bebidas de Inglaterra, Alemania y Holanda; comienza a fabricar cerveza en el país, por lo tanto el uso intenso y la reutilización de los recipientes se torna una práctica común. Las fuentes analizadas y los trabajos de recolección mediante transectas en las inmediaciones del Fortín La Parva, por ejemplo, coinciden con la concentración y diversidad de los objetos de gres, vidrios y lozas. La mayoría del sector comercial de la campaña estaba a cargo de los pulperos dispersos por esa frontera, en los fuertes, fortines y estancias las mujeres tuvieron un rol complejo pero fueron invisibilizadas por las autoridades y la historia del país por demasiado tiempo (Langiano, 2015). En la campaña y en gran parte del siglo XIX, existió un grupo numeroso de pulperos, tratantes y tenderos que estaba dedicado a comerciar al menudeo que abastecía a la población rural.

Los restos de fauna recuperados; en los fuertes y fortines pudieron ser asignados tanto a especies europeas, con predominio de (Bos p. taurus y Equus f. caballus), como a las especies silvestres -cérvidos autóctonos, armadillos, roedores y aves- que aparecen en una proporción menor, principalmente en los sitios de la segunda mitad del siglo XIX. En este punto es de importancia destacar que a medida que se introducía población eurocriolla a la zona de frontera, también se incorporan mayor cantidad de especies europeas para el comercio al exterior y en un segundo plano para el mantenimiento de la población. 
Existen indudablemente, muchas cuestiones para seguir indagando: la dinámica del comercio rural, el valor de uso otorgado a los variados materiales que circulaban en la frontera y sus vinculaciones son algunas de las problemáticas que aún quedan por resolver sobre el complejo mundo rural de la frontera bonaerense de la segunda mitad del siglo XIX, en época de la denominada "Campaña al desierto". Pero excedería el espacio otorgado para este trabajo.

\section{Agradecimientos}

Esta investigación ha sido efectuada gracias a subsidios otorgados al proyecto Una mirada interdisciplinaria en proximidades del Bicentenario de los pueblos al sur del Río Salado bonaerense, 03-PIO-53F, Proyecto de Investigación Orientado (PIO), fortalecimiento III otorgado por la Secretaría de Ciencia y Técnica de la UNICEN. Al INCUAPA-CONICET-UNICEN, de la Facultad de Ciencias Sociales de Olavarría. Nuestro agradecimiento a la Sra. Isabel Bensunsan y al Sr. Eduardo Bernaudo y Lis Solé, por brindarnos su apoyo, por facilitar nuestra investigación y por compartir este ideal de conservación y preservación del patrimonio arqueológico. A las municipalidades de Tandil, Olavarría, Gral. Alvear, Nueve de Julio, Los Toldos y Cnel. Suárez.

\section{Referencias bibliográficas}

Alsina, A. 1977 [1877] La nueva línea de fronteras, Memoria especial del Ministerio de Guerra y Marina. Buenos Aires. Imprenta del Porvenir

Armaignac, H.1974 [1872]. Viaje por las pampas argentinas. Lucha de frontera con el indio. Buenos Aires. Editado por EUDEBA

Barros, A. 1975 [1872]. Fronteras y territorios federales de las Pampas al Sur. Buenos Aires. Editorial Hachette

Barsky, O. y J. Djenderedjian 2003 Historia del capitalismo agrario pampeano. La expansión ganadera hasta 7895. Siglo XXI, Buenos Aires-Ch de Mot 1980 Archivos "Enrique Squirru", de Azul, Histórico de la Provincia de Buenos Aires.

Curtoni, R. P. 2000. "La percepción del paisaje y la reproducción de la identidad social en la región pampeana occidental. (Argentina)". TAPA 19:115-125.

García, P. A.1974 [1836] Diario de un viaje a Salinas Grandes en los Campos del Sud de Buenos Aires. Lucha de Frontera Contra el Indio. Buenos Aires. Editorial Universal de Buenos Aires

Goldman, N. 1998 Los orígenes del federalismo rioplatense (1820-1831), en Nueva Historia Argentina, capítulo III: 103-118.

Gorraiz Beloqui, R. 1958. Tandil a través de un siglo, reseña geográfica, histórica, económica y administrativa 1823-1923. Buenos Aires. Ed. Talleres gráficos J. Héctor Matera Lavalle 1653

Gómez Romero, F. 1999 Sobre lo arado el pasado, arqueología histórica en los alrededores del Fortín Miñana (1860-1869). Azul. Editorial Biblios 
-2002. Arqueología de una pulpería de campaña: Las Vizcacheras (Ayacucho, Provincia de Buenos Aires). Actas del Primer Congreso Nacional de Arqueología Histórica. Editado por Schávelzon, D. y M. Silveira, pp: 417- 427. Buenos Aires. Editorial: Corregidor

Higueras, P. y R. Oyarzun 2010. Mineralogía y geoquímica ambiental: Introducción al curso. http://www. uclm.es/users/higueras/mga/Tema00_Intro.htm Published: 2010-10-29 02:05:40 GMT.

Langiano, M. del C. 2006 Alteración térmica y experiencias de cocción de cerámica con material óseo. En Arqueología Histórica en América Latina, Temas y discusiones recientes. Pedro Paulo A. Funari y Fernando R. Britez (compiladores): 191-218 UNICAMP. Museo de la Vida Rural de General Alvarado (Comandante Ottamendi) y Sociedad Colombiana de Arqueología. Mar del Plata. Argentina.Ediciones Suárez

-2015 Documentos y registro Arqueológico en sociedades de frontera. La pampa bonaerense entre 1850 Y 1890. Tesis Doctoral no publicada, Departamento de Arqueología. Facultad de Ciencias Sociales de Olavarría. Universidad Nacional del Centro de la provincia de Buenos Aires

Langiano, M. del C., J F. Merlo y P. Ormazabal 1997. Arqueología de puestos fortificados en el camino a Salinas. Actas de las primeras jornadas regionales de historia y arqueología del siglo XIX:12-18. Tapalqué.

-2002. "Relevamiento de Fuertes y Fortines, con relación al Camino de los Indios a Salinas". En Del Mar a los Salitrales. Diez mil años de Historia Pampeana en el Umbral del Tercer Milenio, editado por D. L. Mazanti, M. Berón y F. Oliva, pp 53-64. Sociedad Argentina de Antropología. Laboratorio de Arqueología, Facultad de Humanidades. Universidad Nacional de Mar del Plata, Mar del Plata.

Langiano, M. del C., J. Merlo y V. Pedrotta 2009. El Patrimonio Arqueológico de la Antigua Frontera Sur: Fuertes, Fortines y Tolderías. En: Patrimonio, Ciencia y Sociedad. Un abordaje preliminar en los Partidos de Azul, Olavarría y Tandil, pp:235-258. Editado por J. Prado y M. Endere, UNCPBA, Olavarría. Buenos Aires.

Langiano, M. del C. y J. F. Merlo. 2010. Modos de alimentación en la frontera sur bonaerense (siglo XIX). En Zooarqueología a principios del siglo XXI: Aportes teóricos, metodológicos y casos de estudio. M. A. Gutiérrez, M. De Nigris, P. M. Fernández, M.

Giardina, A. F. Gil, A. Izeta, G. Neme Y H. D. Yacobaccio (eds): pp 487-497. Buenos Aires. Libros del Espinillo

Langiano, M. del C. y C. E. Schwartz 2006. Análisis preliminar de materiales arqueológicos procedentes del Fortín La Parva (General Alvear, Pcia. de Buenos Aires) En $9^{\circ}$ Encuentro de Historia y de Arqueología Postconquista de los pueblos al sur del Salado:161-171.. Wally Juan W. Langiano María del Carmen, Merlo Julio F y Alvarez María N. compiladores. Comisión Municipal de Estudios Históricos y Arqueología Histórica. Municipalidad de Olavarría. Imprenta MC. Olavarría.

Lanteri, M. S. 2004. Colonizando la frontera: acceso y tenencia de la tierra en la campaña sur bonaerense en la primera mitad del siglo XIX. El arroyo Azul durante el rosismo. Jornadas" Acceso y tenencia de la tierra en Argentina y Latinoamérica desde los tiempos coloniales hasta la actualidad". Córdoba. Centro de Estudios Históricos Profesor C. Segreti 
Leoni, J. B.; D. Tamburini, T. Acedo y G. Scarafía. 2013. Fortificando el desierto: la transformación del paisaje pampeano en el territorio del actual partido de Carlos Casares, 1869-1877.Anuario de Arqueología, Rosario, 5:149-168.

Lobato, M. Z. y J. Suriano 2010. Nueva Historia Argentina, Atlas Histórico. Buenos Aires. Editorial. Sudamericana

Melcher, F. L. 1873 Plano General de la Frontera de Buenos Aires sobre la Pampa. Encargado por orden del S.E. el señor Ministro de Guerra y Marina Coronel Don Martín de Gainza. Abril 1873.

Merlo, J. F. 1997. Estudio de los Recursos Faunísticos en el Fuerte Blanca Grande (Partido de Olavarría, provincia de Buenos Aires). En Arqueología Uruguaya hacia el fin del milenio. Asociación Uruguaya de Arqueología. Ministerio de Educación y Cultura. Uruguay. Tomo II, pp:557 -563.

-1999. Estudio de los Recursos Faunísticos en el Fuerte Blanca Grande Provincia de Buenos Aires. Trabajo de tesis de grado no publicada. En Biblioteca Central del Campus Universitario (UNICEN), sede en Olavarría. Provincia de Buenos Aires

-2006 Investigaciones actualísticas - Experimentales para la interpretación del registro Arqueofaunísticos en sitios fortificados del siglo XIX. Arqueología Histórica en América Latina Temas y discusiones recientes, pp:219-244. Pedro Paulo A. Funari y Fernando R. Britez (compiladores) UNICAMP. Museo de la Vida Rural de General Alvarado (Comandante Ottamendi) y Sociedad Colombiana de Arqueología. Mar del Plata. Ediciones Suárez

-2014. Aprovechamiento de recursos faunísticos en sitios fortificados de la frontera sur bonaerense en el siglo XIX. Tesis doctoral, UNICEN, Olavarría. -2014

-2015 Investigaciones Arqueofaunísticas en El Fortín La Parva (1858) Anuario de Arqueología, Rosario (2015), 7:165-184.

Merlo, J. F., M. C. Langiano y P. Ormazabal 2008. La utilización del material faunístico como elemento de combustión en sitios fortificados. Continuidad y cambio cultural en arqueología histórica. Actas del Tercer Congreso Nacional de Arqueología Histórica, pp:626-632. Compiladora: María Teresa Carrara. Escuela de Antropología, Facultad de Humanidades y Artes. Universidad Nacional de Rosario.

Merlo, J. F., M. del C. Langiano y R. G. Castro. 2017 (enviado a publicar: 31 - 03 - 2017) Primeros Relevamientos Arqueológicos En El Partido De 9 De Julio (Provincia De Buenos Aires). Boletín Del Centro. Centro de Registro del Patrimonio Arqueológico y Paleontológico de la Provincia de Buenos Aires.

Merlo, J. F. y L. Merlo 2018. Las investigaciones en el Fuerte Blanca Grande Anuario de Arqueología, Rosario. $\mathrm{N}^{\mathrm{o}}$ 10:51-69.

Paladino, C. 1994 Tenemeche. "Situación Histórica de la Blanca Grande". Editado por el Club de Pescadores Ciudad de Olavarría. Buenos Aires;

Paunero, ([ACBBPA]; Carta, $N^{\circ}$ 617, abril de 1864) y en la diseñada por el Departamento Topográfico donde se describe una parte de la Provincia de Buenos Aires y la Pampa con demostración de 
la actual línea de fronteras, las proyectadas por el Gobierno Provincial y el Congreso Nacional ([ACBPA] Carta, $1870 \mathrm{~S} / \mathrm{N})$.

Pedrotta, V. 2002. Arqueología histórica en el Arroyo Nieves (Pdo.de Olavarría): resultados preliminares de los primeros trabajos de campo. Intersecciones en Antropología 3: 125-129.

Politis, G. 1984. Climatic Variations During Historical Times in Eastern Buenos Aires Pampas, Argentina. Cuaternary of South America and Antartic Peninsula. Vol 2, Art. 9:133-162.

Ratto, S. 2003. Una experiencia fronteriza exitosa: el negocio pacífico de indios en la provincia de Buenos Aires (1829-1852). Revista de Indias, vol. LXIII, nº 227: 119-222.

Schávelzon, D. 1991. Arqueología Histórica de Buenos Aires. La cultura material porteña de los siglos XVIII y XIX. Buenos Aires. Ed. Corregidor

Thill, J. P. y J. A. Puigdomenech 2003. Guardias, fuertes y fortines de la Frontera Sur. Historia, antecedentes y ubicación catastral. Tomos I y II. Buenos Aires. Editorial Edivern

Walther, J. C. 1970 La Conquista del Desierto. Lucha de frontera con el indio. Buenos Aires. Editado por EUDEBA

Zeberio, B. 2001. "La situación de los chacareros arrendatarios en la pampa húmeda. Una discusión inacabada" en R. Mandrini y A. Reguera (comps.), Huellas en la tierra, Tandil, IEHS, 1993.

Recibido 18 de Marzo 2021

Aceptado: 30 de Abril 2021 